\title{
Next-generation sequencing of BRCA1 and BRCA2 genes for rapid detection of germline mutations in hereditary breast/ovarian cancer
}

\author{
Arianna Nicolussi $^{1}$ ， Francesca Belardinilli ${ }^{2}$, Yasaman Mahdavian ${ }^{2}$, Valeria Colicchia ${ }^{2}$, Sonia D'Inzeo ${ }^{1,3}$, \\ Marialaura Petroni $^{4}$, Massimo Zani ${ }^{2}$, Sergio Ferraro ${ }^{2}$, Virginia Valentini $^{2}{ }^{\text {, Laura Ottini }}{ }^{2}$, Giuseppe \\ Giannini $^{2,5}$, Carlo Capalbo ${ }^{\text {Corresp., } 2}$, Anna Coppa ${ }^{\text {Corresp. } 1}$ \\ 1 Department of Experimental Medicine, University of Roma "La Sapienza", Roma, Italy \\ 2 Department of Molecular Medicine, University of Roma "La Sapienza", Roma, Italy \\ 3 U.O.C. Microbiology and Virology Laboratory, A.O. San Camillo Forlanini, Roma, Italy \\ 4 Istituto Italiano di Tecnologia, Center for Life Nano Science@Sapienza, Roma, Italy \\ 5 Istituto Pasteur-Fondazione Cenci Bolognetti, Roma, Italy \\ Corresponding Authors: Carlo Capalbo, Anna Coppa \\ Email address: carlo.capalbo@uniroma1.it, anna.coppa@uniroma1.it
}

Background: Conventional methods used to identify BRCA1 and BRCA2 germline mutations in hereditary cancers, such as Sanger sequencing/MLPA, are time-consuming and expensive, due to the large size of the genes. The recent introduction of Next-Generation Sequencing benchtop platforms offered a powerful alternative for mutation detection, dramatically improving the speed and the efficiency of DNA testing. Here we tested the performance of the Ion Torrent PGM platform with the lon AmpliSeq BRCA1 and BRCA2 Panel in our clinical routine of breast/ovarian hereditary cancer syndrome assessment.

Methods: We first tested the NGS approach in a cohort of 11 patients (training set) who had previously undergone genetic diagnosis in our laboratory by conventional methods. Then, we applied the optimized pipeline to the consecutive cohort of 136 uncharacterized probands (validation set).

Results: By minimal adjustments in the analytical pipeline of Torrent Suite Software we obtained a 100\% concordance with Sanger results regarding the identification of single nucleotide alterations, insertions, and deletions with the exception of 3 large genomic rearrangements contained in the training set. The optimized pipeline applied to the validation set, identified pathogenic and polymorphic variants, including a novel BRCA2 pathogenic variant at exon 3,100\% of which were confirmed by Sanger in their correct zygosity status. To identify large genomic rearrangements, all negative samples of the validation set were subjected to MLPA analysis.

Discussion: Our experience strongly supports that the lon Torrent PGM technology in BRCA1 and BRCA2 germline variant identification, combined with MLPA analysis, is highly sensitive, easy to use, faster and cheaper than traditional (Sanger sequencing/MLPA) approaches. 
1 Next-generation sequencing of $B R C A 1$ and $B R C A 2$ genes for rapid detection of

2 germline mutations in hereditary breast/ovarian cancer

3

4 Arianna Nicolussi ${ }^{1}$; Francesca Belardinillii ; Yasaman Mahdavian² ${ }^{2}$, Valeria Colicchia ${ }^{2}$; Sonia

5 D'Inzeo ${ }^{1,3}$; Marialaura Petroni ${ }^{4}$; Massimo Zani²; Sergio Ferraro ${ }^{2}$; Virginia Valentini²; Laura

6 Ottini' $^{2}$; Giuseppe Giannini ${ }^{2,5}$; Carlo Capalbo ${ }^{2 *}$ and Anna Coppa ${ }^{1 *}$

$8 \quad{ }^{1}$ Department of Experimental Medicine, University of Roma "La Sapienza", Italy

9 2Department of Molecular Medicine, University of Roma "La Sapienza", Italy

10 3Present address: A.O. San Camillo Forlanini, U.O.C. Microbiology and Virology Laboratory,

11 Roma, Italy

$12 \quad{ }^{4}$ Center for Life Nano Science@Sapienza, Istituto Italiano di Tecnologia, Roma, Italy

13 Istituto Pasteur-Fondazione Cenci Bolognetti, Roma, Italy

* These authors jointly directed this work

17 Corresponding authors:

Dott.ssa Anna Coppa, Department of Experimental Medicine, University of Roma "La

19 Sapienza", Italy

Dott. Carlo Capalbo, Department of Molecular Medicine, University of Roma "La Sapienza", 21 Italy

22 Email address: anna.coppa@uniroma1.it; carlo.capalbo@uniroma1.it

\section{ABSTRACT}

Background: Conventional methods used to identify $B R C A 1$ and $B R C A 2$ germline mutations in hereditary cancers, such as Sanger sequencing/MLPA, are time-consuming and expensive, due to the large size of the genes. The recent introduction of Next-Generation Sequencing benchtop platforms offered a powerful alternative for mutation detection, dramatically improving the speed and the efficiency of DNA testing. Here we tested the performance of the Ion Torrent PGM platform with the Ion AmpliSeq BRCA1 and BRCA2 Panel in our clinical routine of 
31 breast/ovarian hereditary cancer syndrome assessment.

32 Methods: We first tested the NGS approach in a cohort of 11 patients (training set) who had previously undergone genetic diagnosis in our laboratory by conventional methods. Then, we applied the optimized pipeline to the consecutive cohort of 136 uncharacterized probands

35 (validation set).

Results: By minimal adjustments in the analytical pipeline of Torrent Suite Software we obtained a 100\% concordance with Sanger results regarding the identification of single nucleotide alterations, insertions, and deletions with the exception of 3 large genomic rearrangements contained in the training set. The optimized pipeline applied to the validation set, identified pathogenic and polymorphic variants, including a novel $B R C A 2$ pathogenic variant at exon 3, 100\% of which were confirmed by Sanger in their correct zygosity status. To identify large genomic rearrangements, all negative samples of the validation set were subjected to MLPA analysis.

Discussion: Our experience strongly supports that the Ion Torrent PGM technology in BRCAI and $B R C A 2$ germline variant identification, combined with MLPA analysis, is highly sensitive, easy to use, faster and cheaper than traditional (Sanger sequencing/MLPA) approaches.

\section{INTRODUCTION}

Inherited mutations in highly penetrant $B R C A 1$ and $B R C A 2$ genes occur in about 5-10\% of breast and ovarian cancer disease (Foulkes et al., 2008). A recent prospective cohort study has estimated that the cumulative risks of breast cancer to age 80 years was $72 \%$ for $B R C A 1$ and $69 \%$ for BRCA2 carriers (Kuchenbaecker et al., 2017). A large mutation spectrum has been reported for these genes, as recently revised (Rebbeck et al., 2018). The contribution of lowpenetrance and risk-modifiying genetic polymorphisms to a more appropriate assessment of individual risk is also emerging (Couch et al., 2012; Ottini et al., 2013; Kuchenbaecker et al., 2014; Peterlongo et al., 2015).

Direct Sanger sequencing represented the most common method for over two decades to identify single nucleotide alterations, insertions, and deletions of $B R C A 1$ and $B R C A 2$ in the clinical practice. Large genomic alterations may be detected by the Multiplex Ligation-dependent Probe Amplification (MLPA) assay. Sanger sequencing and MLPA are to date considered the gold standard methods to determine the $B R C A 1$ and $B R C A 2$ mutation status. However, the big size 
62 (5592 bp and $10257 \mathrm{bp}$, respectively), the content in homopolymeric regions and the high-allelic

63 heterogeneity of the genes, together with the lack of mutation hot spots, made the diagnostic

64 procedure time-consuming and costly. The recent improvements in DNA sequencing technology,

65 and the emergence of benchtop Next-Generation Sequencing (NGS) instruments offered a

66 powerful alternative for mutation detection, dramatically improving the speed and the efficiency

67 of DNA testing (Feliubadalo et al., 2013; Yeo et al., 2014; Trujillano et al., 2015). Indeed, NGS

68 significantly speeded the reporting times of hereditary breast/ovarian cancer predisposition,

69 important for rapid clinical management of carriers.

70 The implementation of targeted therapy in solid cancers with Poly(ADP-ribose) polymerase

71 (PARP) inhibitors (O'Sullivan et al., 2015; Colicchia et al., 2017; Stewart et al., 2018) and in

72 particular the observation of their effectiveness in some phase 3 trials carried out in women with

73 BRCA1 or BRCA2 pathogenic variants and metastatic ovarian or advanced breast cancer

(Coleman, et al., 2017; Robson et al., 2017; Oza et al.,2018; Litton et al., 2018), indicate BRCA1

and $B R C A 2$ mutation status as a novel biomarker and highlight the importance of shortening the turn-around time of the analysis for to give results to make possible a faster identification of carriers. To respond to the increasing request of genetic testing, NGS methods are starting to be used routinely in many molecular genetic laboratories including ours.

NGS technology is currently used with several available platforms, such as the Genome

Sequencer (Roche-454 Life Sciences, Indianapolis, IN, USA), the Genome Analyzer/HiSeq/MiSeq (Illumina-Solexa, San Diego, CA, USA), Ion Torrent PGM and Ion Proton sequencers (Thermo Fisher Scientific, Waltham, MA, USA), and the HeliScope from Helicos BioSciences (Cambridge, MA, USA) (Voelkerding et al., 2009; Rothberg et al., 2011; Wallace et al., 2016). Key differences exist in their performance, quality of data and throughput capacity: MiSeq had the highest throughput per run $(1.6 \mathrm{~Gb} / \mathrm{run}, 60 \mathrm{Mb} / \mathrm{h})$ and lowest error rates, 454 GS Junior generated the longest reads (up to 600 bases) but had the lowest throughput ( 70 $\mathrm{Mb} / \mathrm{run}, 9 \mathrm{Mb} / \mathrm{h}$ ), while Ion Torrent PGM had the highest throughput (80-100 Mb/h) (Loman et al., 2012). Ion Torrent PGM is a new sequencing platform that substantially differs from other sequencing technologies by measuring $\mathrm{pH}$ rather than light to detect polymerization events. It represents the first 'post-light' sequencing instrument that exploits the emulsion PCR and incorporates a sequencing-by-synthesis approach. All four nucleotides are provided in a stepwise fashion during an automated run. When the nucleotides, complementary to the template are 
93 incorporated into the nascent strand, the hydrolysis of the incoming nucleotide triphosphate

94 causes the net liberation of a single proton for each nucleotide incorporated, producing a shift in

95 the $\mathrm{pH}$ of the surrounding solution detected by a modified silicon chip (Rothberg et al., 2011).

96 Ion Torrent PGM offer three differently priced sequencing-chip reagents, giving a large

97 flexibility in designing experiments, as a choice can be made based on the throughput required.

98 In the present study, we evaluated the performance of the Ion Torrent PGM platform in

99 combination with the ready-to-use Ion AmpliSeq BRCA1 and BRCA2 Panel (Life Technologies)

100 in the diagnostic screening for the identification of single nucleotide alterations, insertions, and

101 deletions in BRCA1 and BRCA2 genes.

102

103 MATERIALS \& METHODS

104 Patients and DNA

105 A retrospective cohort of 11 familial breast cancer patients, training set (TS), previously tested

106 by Sanger sequencing for all $B R C A 1$ and $B R C A 2$ exons and by MLPA to detect LGRs, and a

107 prospective consecutive cohort of 136 uncharacterized probands, validation set (VS), enrolled at

108 the Hereditary Tumors section of Policlinico Umberto I, University La Sapienza, between July

1092015 and September 2017, were analyzed. Selection criteria were as follows: (i) three or more

110 breast cancer cases diagnosed at any age or two first-degree family members affected before 50;

111 (ii) early onset breast cancer ( $<35$ years); (iii) breast and ovarian cancer in the same individual or

112 two breast cancer cases and at least one ovarian cancer case, or one breast cancer case and one

113 ovarian cancer case diagnosed before 50 in first-degree family members; (iv) male breast cancer;

114 (v) BRCAPro5 greater than 10\% (Capalbo et al., 2006a; Capalbo et al., 2006b; Coppa et al.,

115 2014).

116 Comprehensive pre-test counseling was offered to all probands and their family members and

117 informed consent was obtained. The TS was characterized by 11 samples carrying 11 different

118 pathogenic mutations including Single Nucleotide Variants (SNVs), indels and large genomic

119 rearrangements (LGRs) plus 37 benign variants (Table 1 and Table S1).

120 Genomic DNA was extracted from peripheral blood samples using a commercial kit (QIAamp

121 Blood Kit, Qiagen, Valencia, CA) according to the manufacturer's instructions. All

122 investigations were approved by Ethics Committee of the University of Roma "La Sapienza" 
123 (Prot.: 88/18; RIF.CE:4903, 31-01-2018) and conducted according to the principles outlined in

124 the declaration of Helsinki.

125

\section{Ion Torrent PGM Library Preparation}

127 The entire coding regions of the $B R C A 1$ and $B R C A 2$ genes were amplified using the Ion 128 AmpliSeq BRCA1 and BRCA2 Panel (Life Technologies) consisting of three primer pools, 129 covering the target regions in 167 amplicons, including all exons and 10 to $20 \mathrm{bp}$ of intronic

130 flanking sequences, for both genes. Ion Torrent adapter-barcode ligated libraries were generated 131 using Ion AmpliSeq ${ }^{\mathrm{TM}}$ Library Kit 2.0 (Applied Biosystems, Life Technologies) and Ion 132 Xpress $^{\mathrm{TM}}$ Barcode Adapter 1-16 Kit (Applied Biosystems, Life Technologies) according to the 133 manufacturer's procedures to obtain 200-bp PCR fragments flanked by adaptor and barcode 134 sequences, allowing sequencing and sample identification, respectively. In brief, DNA 135 concentration was measured with Qubit ${ }^{\mathrm{TM}}$ dsDNA HS Assay Kit (Thermo Fisher Scientific, 136 Waltham, MA, USA) and Qubit ${ }^{\circledR}$ Fluorometer (Thermo Fisher Scientific, Waltham, MA, USA). 13710 ng of each genomic DNA sample was amplified, using Ion AmpliSeq ${ }^{\mathrm{TM}} \mathrm{HiFi}$ Master Mix 138 (Applied Biosystems, Life Technologies) and Ion AmpliSeq ${ }^{\mathrm{TM}}$ BRCA1 and BRCA2 Community 139 Panel primer pools (3 pools), for $2 \mathrm{~min}$ at $99^{\circ} \mathrm{C}$, followed by 19 two-step cycles of $99^{\circ} \mathrm{C}$ for 15 $140 \mathrm{sec}$ and $60^{\circ} \mathrm{C}$ for $4 \mathrm{~min}$, ending with a holding period at $10^{\circ} \mathrm{C}$ in a GeneAmp PCR System 9700 141 thermocycler (Applied Biosystems, Houston, USA). The amplified DNA samples were digested, 142 then barcodes and adapters were ligated to the amplicons as previously described (Belardinilli et 143 al., 2015) and reported in Ion AmpliSeq library preparation manual. Adaptor ligated amplicon 144 libraries were purified with the Agencourt AMPure XP system (Beckman Coulter Genomics, 145 Danvers, MA). Following Agencourt AMPure XP purification, the concentration of the libraries 146 was determined using the Qubit ${ }^{\mathrm{TM}}$ dsDNA HS Assay Kit (Thermo Fisher Scientific, Waltham, 147 MA, USA) and Qubit ${ }^{\circledR}$ Fluorometer (Thermo Fisher Scientific, Waltham, MA, USA). After 148 quantification, each amplicon library was diluted to $50 \mathrm{pM}$ and the same amount of the 12 149 libraries for 4 patients (Chip314v2) or 24 libraries for 8 patients (Chip316v2) was pooled to 150 perform the emulsion PCR reaction and the sequence reaction.

\section{Emulsion PCR and Sequencing}

153 The emulsion PCR was carried out with the Ion OneTouch 2 System and Ion Torrent PGM Hi-Q 
154 OT2 Kit (Thermo Fisher Scientific, Waltham, MA, USA) according to the manufacturer's

155 procedure. Template-positive Ion Sphere ${ }^{\text {TM }}$ Particles were enriched with the Dynabeads MyOne

156 Streptavidin C1 Beads (Thermo Fisher Scientific, Waltham, MA, USA) and washed with Ion

157 OneTouch Wash Solution. This process was performed using an Ion OneTouch ES system

158 (Thermo Fisher Scientific, Waltham, MA, USA). After the Ion Sphere Particle preparation,

159 Massive Parallel Sequencing was carried out with Ion Torrent PGM sequencer system (Thermo

160 Fisher Scientific, Waltham, MA, USA) using the Ion Torrent PGM Hi-Q Sequencing Kit and Ion

$161314 v 2$ or 316v2 Chip (Thermo Fisher Scientific, Waltham, MA, USA), according to the

162 established procedures.

163

164 Data Analysis

165 Raw sequence data analysis, including base calling, demultiplexing, alignment to the hg19

166 human reference genome (Genome Reference Consortium GRCh37), was performed using the

167 Torrent Suite Software version 3.6 and subsequent versions up to 5.2 (Thermo Fisher). The

168 average depth of total coverage was set at minimum 500x and for variant calls at minimum of

$169100 x$.

170 The TS data were processed using Coverage Analysis and Variant Caller (germline low

171 stringency) plugins available within the Torrent Suite Software version 3.6 using default analysis

172 settings and subsequently using the version 3.6 of json parameters file associated with the

$173 B R C A 1$ and BRCA2 Ion Ampliseq Panel. The VS data were processed using Coverage Analysis

174 and Variant Caller plugins available within the Torrent Suite Software versions from 4.0 to 5.2

175 and the json parameters file associated with the BRCA1 and BRCA2 Ion Ampliseq Panel.

176 All the variants were visually examined and verified using Integrative Genomics Viewer (IGV)

177 version 5.01 (http://www.broadinstitute.org/igv) as well as by filtering out possible strand-

178 specific errors (i.e. mutations detected exclusively in the "plus" or in the "minus" strand, but not

179 in both DNA strands). All mutations are reported following the Human Genome Variation

180 Society (HGVS) guidelines (http://www.hgvs.org/mutnomen/) on the basis of the coding

181 sequences NM_007294.3 and NM_000059.3 for BRCA1 and BRCA2, respectively. Common

182 polymorphisms, that represent $5 \%$ in the general population, and variant of uncertain

183 significance (VUS) or pathogenic variants were classified referring to the following databases:

184 Breast Cancer Information Core BIC (https://research.nhgri.nih.gov/), Clinical Variants 
185 (https://www.ncbi.nlm.nih.gov/pubmed), dbSNP138

186 (https://www.ncbi.nlm.nih.gov/projects/SNP/), ARUP (http://arup.utah.edu/database/ BRCA/),

187 Universal Mutation Database (UMD) (http://www.umd.be/BRCA1/,

188 http://www.umd.be/BRCA2/), Leiden Open (source) Variation Database (LOVD)

189 (http://www.lovd.nl/3.0/home). Unclassified variants were evaluated by the following in silico

190 predictors: SIFT-PROVEAN (http://provean.jcvi.org/index.php), Polyphen (http://genetics.bwh.

191 harvard.edu/pph2/), GVGD (http://agvgd.hci.utah.edu/agvgd_input.php), Mutation taster

192 (http://www.mutationtaster.org/), Fruit Fly Splice Predictor, NNSPLICE

193 (http://www.fruitfly.org/seq_tools/splice.html), Human Splicing Finder

194 (http://www.umd.be/HSF3/), Splice Predictor (DK), NetGene2 (http://www.cbs.dtu.dk/

195 services/NetGene2/), MaxEntScan

196 (http://genes.mit.edu/burgelab/maxent/Xmaxentscan_scoreseq. html), ESEfinder3.0

197 (http://rulai.cshl.edu/cgi-bin/tools/ESE3/esefinder.cgi? process=home). The meaning of the

198 variants not yet reported in the literature and in the databases was established as described by

199 Giannini et al. (Giannini et al., 2008), according to ENIGMA criteria

200 (https://enigmaconsortium.org/).

201 Concordance of the NGS results with respect to those obtained with Sanger sequencing was

202 calculated using classifications as true positive (TP), true negative (TN), false negative (FN), or

203 false positive (FP). Regarding specificity and negative predictive value (NPV), since these

204 parameters are calculated considering true negatives (TNs), we considered the number of wild-

205 type bases that were called by NGS and aligned to the reference sequence.

206

207 Sanger sequencing

208 A subset of clinical samples (11 samples of TS and 60 samples of VS) were sequenced for the

209 entire coding regions by Sanger sequencing. Sequencing was performed using an ABI PRISM

210 DyeDeoxy Terminator Cycle Sequencing Kit and an ABI 3100 Genetic Analyzer (Applied

211 Biosystems, Warrington, UK) according to Coppa et al. (Coppa et al., 2018).

212 Reference sequence for BRCA1 was Genebank, NM_007294.3, and reference sequence for

213 BRCA2 was Genebank, NM_000059.3.

214

215

MLPA assay 
216 BRCA1 and BRCA2 genomic rearrangements were searched by the Multiple-Ligation-dependent-

217 Probe-Amplification (MLPA) methodology (Schouten et al., 2002) according to the manufacturer's

218 instructions (MRC-Holland, Amsterdam, The Netherlands) and as described (Buffone et al., 2007;

219 Coppa et al., 2018) Variations in peak height were evaluated comparing each sample with a normal

220 control and by a cumulative comparison.

221

222 RESULTS

\section{Coverage data analysis}

224 The $B R C A 1$ and $B R C A 2$ panel used in this study generates 167 amplicons that cover all targeted

225 coding exons and exon-intron boundaries. The data coverage in 147 patients (TS and VS)

226 showed a mean amplicon reading depth per sample ranging from $244 \mathrm{x}$ to $2236 \mathrm{x}$, loading $2 / 4$

227 samples on chips $314 \mathrm{v} 2$ or 8 samples on chip 316v2. An adequate number of reads mapped onto

228 target regions has been obtained both with chip314v2 or chip316v2, with a mean sequencing

229 depth and an average uniformity of coverage of $726 \times$ and $97 \%$ and $1504 x$ and $97 \%$, respectively

230 (Table 2, Table S2 and Table S3). The large increase in sequencing efficiency observed with the

$231316 \mathrm{v} 2$ chips makes the analysis of a better quality and led to a lower number of false-positive

232 indel calls. For variant calls, we chose the threshold of a minimum average depth of 100x,

233 although a minimum average of $80 \mathrm{x}$ is normally required for germline mutations (Trujillano et

$234 a 1 ., 2015$ ) and a minimum average depth in strand bias of 30x for each strand end to end. By a

235 critical analysis of the $B R C A 1$ and $B R C A 2$ coverage data performed on 147 samples (TS and VS)

236 emerged that some amplicons (herein defined as lower-performance amplicons) often did not

237 reach a minimum coverage of 100x or showed fwd/rev end to end unbalance (Table 3 and Fig.

238 1). In particular, the coverage of the AMPL225438570 BRCA1 amplicon was $<100 \mathrm{x}$ in $61 \%$ of

239 samples (Fig. 1A). This amplicon maps in the exon 2 of the BRCA1 gene, containing a large A-T

240 reach region, likely to be responsible for lower amplification efficiency. Concerning $B R C A 2$, we

241 observed five amplicons with a coverage less than 100x, whose GC content, self-

242 annealing/hairpin formation and GC clamp issues could be responsible for low performance

243 (Table 3 and Fig. 1B). The same issues may also be responsible for fwd/rev end to end unbalance

244 observed in the following amplicons: AMPL223735053, AMPL223413081, AMPL223712774 in

245 BRCA1 (Fig. 1C, Fig. 1D and Table 3); AMPL224626553, AMPL223938117,

246 AMPL223512592, AMPL225349438, AMPL223730984, AMPL223515418, AMPL225441321, 
247 AMPL223959719 in BRCA2 (Fig. 1E, Fig. 1F and Table 3). Of note, the read depths of these

248 amplicons did not increase proportionally with an increase in mean amplicon read depths (across

249167 amplicons) per sample. No variants have been identified in lower-performance amplicons in

250 our TS and VS samples, using Ion AmpliSeq BRCA1 and BRCA2 Panel (Life Technologies).

251 However, all amplicons with strand bias were carefully and visually verified with IGV and re-

252 analyzed by Sanger sequencing that confirmed the absence of variants.

253

\section{Detection of $B R C A 1$ and $B R C A 2$ variants}

255 The TS, used to test the performance of the Ion AmpliSeq BRCA1 and BRCA2 Panel (Life

256 Technologies) on Ion Torrent PGM platform, contained 6 BRCA1 and 5 BRCA2 pathogenic

257 variants previously identified (Table 1) plus 37 benign variants known (Table S1). Data obtained

258 by Ion Torrent PGM sequencing were blindly analyzed by the Torrent Suite Software version 3.6

259 using Variant Caller plugin (germline low stringency) and subsequently the specific json file.

260 Straightforward default analysis only identified 6 out of $11 B R C A 1$ and $B R C A 2$ pathogenic

261 variants, 4 indel and 2 SNV (Fig. 2, Figure S1). Setting the kmer length parameter value to 11

262 instead of the default value 19, allowed detection of the otherwise missed BRCA1 indel

263 c.4964_4982del19 (p.Ser1655Tyrfs) localized at the end of exon 16 (Fig. 3A), without

264 generating false negative (FN).

265 To detect the BRCA2 complex variant c.7921_7926delGAATTTinsAG (p.Glu2641Argfs) the

266 generation of "complex variant candidates parameter" in the Torrent Suite Software has been

267 activated (Fig. 3B). In this way, the NGS analysis correctly identified a total of 179 variants (68

268 in $B R C A 1$ and 111 in $B R C A 2)$, reaching the maximum sensitivity of 98,3\% (95,3\% for $B R C A 1$

269 and $100 \%$ for $B R C A 2$ ) identifying 8 out 11 pathogenic variants, missing only the three $B R C A 1$

270 LGRs (Table 4). NGS called 8 FPs variants (7 in BRCA1 and 1 in BRCA2) in the 11 samples of

271 TS in the homopolymeric regions of the genes. The positive predictive value (PPV), calculated

272 as (TPs/TPs+ FPs), was $95.5 \%$ (89.7\% for BRCA1 and $99.1 \%$ for $B R C A 2)$. The panel covers

27316246 nucleotides (5989 for $B R C A 1$ and 10,257 for $B R C A 2$ ) for patient, then we covered 178706

274 nucleotides (65879 for BRCA1 and 112827 for BRCA2) in the TS. If we consider that TNs could

275 be calculated as the total analyzed nucleotides-TPs-FPs-FNs, we could calculate a total of

$276178524 \mathrm{TNs}$, that is 65808 for $B R C A 1$ and 112716 for $B R C A 2$. The specificity, calculated as

$277 \mathrm{TN} /(\mathrm{TN}+\mathrm{FP})$, and the negative predictive value (NPV), calculated as $\mathrm{TN} /(\mathrm{TN}+\mathrm{FN})$, were $100 \%$ 
278 (Table 4). Therefore, considering LGRs as FNs, the concordance with Sanger sequencing 279 analysis was $100 \%$.

280 All these data indicated that an appropriate setting of the analytical pipeline can affect the 281 accuracy of a variant call.

282 This optimized pipeline was then blindly applied on the VS of 136 samples, whose genotype was 283 unknown. We detected pathogenic variants in 30 (22\%) cases, 20 in BRCAl (15\%), 10 in BRCA2 284 (7\%), 1 BRCA1 VUS, and 1 BRCA2 VUS. All variants were confirmed by Sanger sequencing in 285 their correct zygosity status (Table 5). The remain 104 samples, negative for pathogenic variants, 286 subjected to MLPA analysis were also negative for the presence of LGRs. Of note, one of the 287 BRCA2 deleterious mutations (c.72delA) was a novel disease causing variant at exon 3, predicted 288 to code for an early truncated protein (p.Gly25Aspfs), thus falling into class V (Plon et al., 2008; 289 ENIGMA consortium: https://enigmaconsortium.org/library/general-documents/enigma-

290 classification-criteria/). The novel mutation has been identified in one HBC family having a 291 clear dominant inheritance pattern and with three cases of breast cancer before 40 years age 292 (Figure S2). It has not yet been possible to perform segregation analysis in this family.

293 A complete $B R C A 1$ and $B R C A 2$ Sanger sequencing has been performed in 60 negative samples 294 of VS (included in the 104 negative samples), because their higher expectation to be carrier of 295 pathogenic mutations. As expected, Sanger sequencing not only confirmed the absence of $296 B R C A 1$ and $B R C A 2$ pathogenic variants, but also identified all benign variants in their correct 297 zygosity status as detected by NGS (Table S4). The variants located in regions not covered by 298 the respective primers have been excluded from this evaluation. Altogether, our data strongly 299 suggest that Ion Torrent PGM and Ion AmpliSeq BRCA1 and BRCA2 Panel (Life Technologies) 300 represent an excellent system to be applied in the field of diagnostics with $100 \%$ of concordance 301 and sensitivity compared to Sanger method.

302 Our study enabled us to generate a standardized diagnostic workflow useful in clinical practice to 303 quickly screen the BRCA1 and BRCA2 genes (Fig. 4).

\section{Cost efficiency and turn-around time (TAT)}

306 In comparison to traditional Sanger-based sequencing, the NGS workflow led to a reduction in 307 cost, analysis time and turn-around time (TAT) for the screening of BRCA1 and BRCA2 genes. 308 Considering the routine of our laboratory, which include PCR and Sanger sequencing, we 
309 calculated that we analyzed 8 samples in 30-40 days. While, with the advent of NGS methodology

310 we can analyze 8 patients in 10 days, making the results available for the clinician in 15 working

311 days following blood sampling. Costs entailed are obviously site-dependent, we calculated a cost

312 of about 1500-3000 euro/sample for BRCA1 and BRCA2 Sanger-based sequencing, and a

313 consistent reduction to about 300 euro/sample with NGS.

314

\section{DISCUSSION}

316 NGS methods are considered a promising technology, that reduces the cost and turn-

317 around time of sequencing analysis. It can also be used to analyze multiple genes in a single run,

318 greatly simplifying the study of complex hereditary disease where Sanger sequencing is not

319 technically or economically feasible. Hence, many molecular genetic laboratories, including

320 ours, are starting to use routinely this technology for diagnostic purpose (De Leeneer et al.,

321 2011; Michils et al., 2012; Chan et al. 2012; Feliubadalo et al., 2013).

322 Recently, different platforms have been validated showing a comparable quality of data

323 and throughput capacity (Voelkerding et al., 2009; Rothberg et al., 2011; Loman et al., 2012;

324 Wallace et al., 2016). In this study, we validated the Ion Torrent PGM platform in combination

325 with the ready-to-use Ion AmpliSeq BRCA1 and BRCA2 Panel (Life Technologies), as, in our

326 opinion, it may be a good candidate for clinical BRCA1 and BRCA2 sequencing. BRCA genes are

327 also involved in the development of sporadic breast and ovarian tumors; and patients, carrying a

328 germline or somatic $B R C A 1 / B R C A 2$ variants, may benefit from PARP inhibitors therapy

329 (Coleman, et al., 2017; Robson et al., 2017; Oza et al.,2018; Litton et al., 2018). Investigating

$330 B R C A 1$ and $B R C A 2$ mutation status in ovarian and breast cancer tissues patients, has a key role

331 in addressing the therapeutic choices. Several studies demonstrated that NGS could be an

332 efficient method for detecting somatic mutations in BRCA1 and BRCA2 genes using DNA from

333 formalin-fixed and paraffin-embedded (FFPE) breast and ovarian cancer tissues (Ellison G et al

334 2015; Mafficini et al 2016; Enyedi et al., 2016). In our laboratory the Ion Torrent PGM platform

335 is currently used for the routine molecular characterization of FFPE tumor tissues from colon or

336 lung cancers patients (Belardinilli et al., 2015) with a highly satisfactory performance.

337 The accuracy of NGS approach represents an important requirement in diagnostic

338 applications, and it strongly depends on the read depth and on the analytical pipeline (Goldfeder

339 et al., 2016). In our tests, we achieved an acceptable sequencing depth and average uniformity of 
340 amplicons coverage in all samples. 60 of the $104 B R C A 1$ and $B R C A 2$ negative samples, that

341 showed a higher expectation to be carrier of pathogenic mutations (i.e. HBC with BRCAPro5.1

342 greater than $40 \%$, Male Breast Cancer or HBOC cases), were also subjected to BRCA1 and

343 BRCA2 Sanger sequencing. We observed $100 \%$ sensitivity and $100 \%$ concordance as well as

344 correct estimate heterozygote and homozygote status.

345 A limit of Ion AmpliSeq BRCA1 and BRCA2 Panel (Life Technologies) is represented

346 by the small group of lower-performance amplicons, that either did not reach a minimum

347 coverage of 100x, as also reported by Pilato et al. (Pilato et al., 2016), or showed fwd/rev end to

348 end unbalance. The mean amplicon read depth could be affected by the large A-T reach region or

349 GC content, self-annealing/hairpin formation and/or GC clamp issues (Yan et al., 2016). We

350 overcame these limits performing, in all samples, Sanger sequencing for the regions covered by

351 low performance amplicons. In addition, the presence of highly homopolymeric regions in the

$352 B R C A 1$ and BRCA2 genes and the nature of semiconductor sequencing chemistry of Ion Torrent

353 PGM were shown to limit the correct call of indel variants in these regions (Yeo et al., 2014;

354 Zanella et al., 2017). Nonetheless, we did not observe incorrect calls in these regions in our 355 samples.

356 A complete clinical level analysis of $B R C A 1$ and $B R C A 2$ includes the study of LGRs. In

357 our experience, the Ion AmpliSeq BRCA1 and BRCA2 Panel (Life Technologies) was not

358 feasible for analyzing copy number alteration due to the sequencing read length (range, 71-239

359 bp) and to the high number of false positive obtained (Pilato et al., 2016). Therefore, the MLPA

360 analysis is always required using this panel. More recently, Thermo Fisher Scientific's developed

361 Oncomine $^{\circledR}$ BRCA Research Panel, that seems to solve all these issues (Hirotsu et al., 2017).

362 Noteworthy, we identified also a novel disease-causing mutation at exon 3 of BRCA2

363 gene in one HBC family. Our results demonstrated that Torrent Suite Software with the

364 appropriate adjustments achieved 100\% sensitivity (considering LGRs as FNs) and the $100 \%$

365 concordance with Sanger sequencing analysis, as well as correct estimate heterozygote and

366 homozygote status from variant frequencies.

367

\section{CONCLUSIONS}

369 In conclusion, our study, according to other published works (Feliubadalo et al., 2013; Yeo et

370 al., 2014; Trujillano et al., 2015), shows that NGS performed with a commercial panel (Ion 
371 AmpliSeq BRCA1 and BRCA2 Panel, Life Technologies) is highly efficient for the detection of

372 germline mutations in $B R C A 1$ and $B R C A 2$ genes using DNA samples from routinely available

373 patients. Moreover, the costs of NGS technology are largely lower (about 300 euros/patient),

374 compared with conventional methods, with a substantial reduction (about 50\%) in analysis time

375 and turn-around time. In our experience, the NGS achieves a perfect sensitivity and the accuracy

376 of Sanger sequencing, becoming an indispensable instrument for routine diagnostic testing on

377 BRCA1 and BRCA2 genes.

378

379

380

\section{ACKNOWLEDGEMENTS}

381 The authors would like to thank Valentina Silvestri for advice on data analysis.

382

383

384

385

386

387

388

389

390

391

392

393

394

395

396

397

398

399

400

401

\section{REFERENCES}

1. Foulkes WD. 2008. Inherited susceptibility to common cancers. The New England Journal of Medicine 359(20):2143-2153. doi:10.1056/NEJMra0802968.

2. Kuchenbaecker KB, Hopper JL, Barnes DR, Phillips KA, Mooij TM, Roos-Blom MJ, Jervis S, van Leeuwen FE, Milne RL, Andrieu N, Goldgar DE, Terry MB, Rookus MA, Easton DF, Antoniou AC; BRCA1 and BRCA2 Cohort Consortium, McGuffog L, Evans DG, Barrowdale D, Frost D, Adlard J, Ong KR, Izatt L, Tischkowitz M, Eeles R, Davidson R, Hodgson S, Ellis S, Nogues C, Lasset C, Stoppa-Lyonnet D, Fricker JP, Faivre L, Berthet P, Hooning MJ, van der Kolk LE, Kets CM, Adank MA, John EM, Chung WK, Andrulis IL, Southey M, Daly MB, Buys SS, Osorio A, Engel C, Kast K, Schmutzler RK, Caldes T, Jakubowska A, Simard J, Friedlander ML, McLachlan SA, Machackova E, Foretova L, Tan YY, Singer CF, Olah E, Gerdes AM, Arver B, Olsson H. 2017. Risks of Breast, Ovarian, and Contralateral Breast Cancer for BRCA1 and BRCA2 Mutation Carriers. JAMA 317(23):2402-2416. doi:10.1001/jama.2017.7112.

3. Rebbeck TR, Friebel TM, Friedman E, Hamann U, Huo D, Kwong A, Olah E, Olopade OI, Solano AR, Teo SH, Thomassen M, Weitzel JN, Chan TL, Couch FJ, Goldgar DE, Kruse TA, Palmero EI, Park SK, Torres D, van Rensburg EJ, McGuffog L, Parsons MT, Leslie G, Aalfs CM, Abugattas J, Adlard J, Agata S, Aittomäki K, Andrews L, Andrulis IL, Arason A, Arnold N, Arun BK, Asseryanis E, Auerbach L, Azzollini J, Balmaña J, 
402

403

404

405

406

407

408

409

410

411

412

413

414

415

416

417

418

419

420

421

422

423

424

425

426

427

428

429

430

431

432
Barile M, Barkardottir RB, Barrowdale D, Benitez J, Berger A, Berger R, Blanco AM, Blazer KR, Blok MJ, Bonadona V, Bonanni B, Bradbury AR, Brewer C, Buecher B, Buys SS, Caldes T, Caliebe A, Caligo MA, Campbell I, Caputo SM, Chiquette J, Chung WK, Claes KBM, Collée JM, Cook J, Davidson R, de la Hoya M, De Leeneer K, de Pauw A, Delnatte C, Diez O, Ding YC, Ditsch N, Domchek SM, Dorfling CM, Velazquez C, Dworniczak B, Eason J, Easton DF, Eeles R, Ehrencrona H, Ejlertsen B; EMBRACE, Engel C, Engert S, Evans DG, Faivre L, Feliubadaló L, Ferrer SF, Foretova L, Fowler J, Frost D, Galvão HCR, Ganz PA, Garber J, Gauthier-Villars M, Gehrig A; GEMO Study Collaborators, Gerdes AM, Gesta P, Giannini G, Giraud S, Glendon G, Godwin AK, Greene MH, Gronwald J, Gutierrez-Barrera A, Hahnen E, Hauke J; HEBON, Henderson A, Hentschel J, Hogervorst FBL, Honisch E, Imyanitov EN, Isaacs C, Izatt L, Izquierdo A, Jakubowska A, James P, Janavicius R, Jensen UB, John EM, Vijai J, Kaczmarek K, Karlan BY, Kast K, Investigators K, Kim SW, Konstantopoulou I, Korach J, Laitman Y, Lasa A, Lasset C, Lázaro C, Lee A, Lee MH, Lester J, Lesueur F, Liljegren A, Lindor NM, Longy M, Loud JT, Lu KH, Lubinski J, Machackova E, Manoukian S, Mari V, Martínez-Bouzas C, Matrai Z, Mebirouk N, Meijers-Heijboer HEJ, Meindl A, Mensenkamp AR, Mickys U, Miller A, Montagna M, Moysich KB, Mulligan AM, Musinsky J, Neuhausen SL, Nevanlinna H, Ngeow J, Nguyen HP, Niederacher D, Nielsen HR, Nielsen FC, Nussbaum RL, Offit K, Öfverholm A, Ong KR, Osorio A, Papi L, Papp J, Pasini B, Pedersen IS, Peixoto A, Peruga N, Peterlongo P, Pohl E, Pradhan N, Prajzendanc K, Prieur F, Pujol P, Radice P, Ramus SJ, Rantala J, Rashid MU, Rhiem K, Robson M, Rodriguez GC, Rogers MT, Rudaitis V, Schmidt AY, Schmutzler RK, Senter L, Shah PD, Sharma P, Side LE, Simard J, Singer CF, Skytte AB, Slavin TP, Snape K, Sobol H, Southey M, Steele L, Steinemann D, Sukiennicki G, Sutter C, Szabo CI, Tan YY, Teixeira MR, Terry MB, Teulé A, Thomas A, Thull DL, Tischkowitz M, Tognazzo S, Toland AE, Topka S, Trainer AH, Tung N, van Asperen CJ, van der Hout AH, van der Kolk LE, van der Luijt RB, Van Heetvelde M, Varesco L, Varon-Mateeva R, Vega A, Villarreal-Garza C, von Wachenfeldt A, Walker L, WangGohrke S, Wappenschmidt B, Weber BHF, Yannoukakos D, Yoon SY, Zanzottera C, Zidan J, Zorn KK, Hutten Selkirk CG, Hulick PJ, Chenevix-Trench G, Spurdle AB, Antoniou AC, Nathanson KL. 2018. Mutational spectrum in a worldwide study of 29,700 
families with BRCA1 or BRCA2 mutations. Hum Mutation 39(5):593-620. doi:10.1002/humu.23406. J, Chen X, Wang X, Kirchhoff T, McGuffog L, Barrowdale D, Lee A, Healey S, Sinilnikova OM, Andrulis IL; OCGN, Ozcelik H, Mulligan AM, Thomassen M, Gerdes AM, Jensen UB, Skytte AB, Kruse TA, Caligo MA, von Wachenfeldt A, Barbany-Bustinza G, Loman N, Soller M, Ehrencrona H, Karlsson P; SWEBRCA, Nathanson KL, Rebbeck TR, Domchek SM, Jakubowska A, Lubinski J, Jaworska K, Durda K, Zlowocka E, Huzarski T, Byrski T, Gronwald J, Cybulski C, Górski B, Osorio A, Durán M, Tejada MI, Benitez J, Hamann U, Hogervorst FB; HEBON, van Os TA, van Leeuwen FE, Meijers-Heijboer HE, Wijnen J, Blok MJ, Kets M, Hooning MJ, Oldenburg RA, Ausems MG, Peock S, Frost D, Ellis SD, Platte R, Fineberg E, Evans DG, Jacobs C, Eeles RA, Adlard J, Davidson R, Eccles DM, Cole T, Cook J, Paterson J, Brewer C, Douglas F, Hodgson SV, Morrison PJ, Walker L, Porteous ME, Kennedy MJ, Side LE; EMBRACE, Bove B, Godwin AK, Stoppa-Lyonnet D; GEMO Study Collaborators, Fassy-Colcombet M, Castera L, Cornelis F, Mazoyer S, Léoné M, BoutryKryza N, Bressac-de Paillerets B, Caron O, Pujol P, Coupier I, Delnatte C, Akloul L, Lynch HT, Snyder CL, Buys SS, Daly MB, Terry M, Chung WK, John EM, Miron A, Southey MC, Hopper JL, Goldgar DE, Singer CF, Rappaport C, Tea MK, Fink-Retter A, Hansen TV, Nielsen FC, Arason A, Vijai J, Shah S, Sarrel K, Robson ME, Piedmonte M, Phillips K, Basil J, Rubinstein WS, Boggess J, Wakeley K, Ewart-Toland A, Montagna M, Agata S, Imyanitov EN, Isaacs C, Janavicius R, Lazaro C, Blanco I, Feliubadalo L, Brunet J, Gayther SA, Pharoah PP, Odunsi KO, Karlan BY, Walsh CS, Olah E, Teo SH, Ganz PA, Beattie MS, van Rensburg EJ, Dorfling CM, Diez O, Kwong A, Schmutzler RK, Wappenschmidt B, Engel C, Meindl A, Ditsch N, Arnold N, Heidemann S, Niederacher D, Preisler-Adams S, Gadzicki D, Varon-Mateeva R, Deissler H, Gehrig A, Sutter C, Kast K, Fiebig B, Heinritz W, Caldes T, de la Hoya M, Muranen TA, Nevanlinna H, Tischkowitz MD, Spurdle AB, Neuhausen SL, Ding YC, Lindor NM, Fredericksen Z, Pankratz VS, Peterlongo P, Manoukian S, Peissel B, Zaffaroni D, Barile M, Bernard L, Viel A, Giannini G, Varesco L, Radice P, Greene MH, Mai PL, Easton DF, Chenevix-Trench G; kConFab investigators, Offit K, Simard 
$\mathrm{J}$; Consortium of Investigators of Modifiers of BRCA1/2. 2012. Common variants at the

465

466

467

468

469

470

471

472

473

474

475

476

477

478

479

480

481

482

483

484

485

486

487

488

489

490

491

492

493

494 19p13.1 and ZNF365 loci are associated with ER subtypes of breast cancer and ovarian cancer risk in BRCA1 and BRCA2 mutation carriers. Cancer epidemiology, biomarkers and prevention 21(4):645-657. doi:10.1158/1055-9965.

5. Ottini L, Silvestri V, Saieva C, Rizzolo P, Zanna I, Falchetti M, Masala G, Navazio AS, Graziano V, Bianchi S, Manoukian S, Barile M, Peterlongo P, D'Amico C, Varesco L, Tommasi S, Russo A, Giannini G, Cortesi L, Viel A, Montagna M, Radice P, Palli D. 2013. Association of low-penetrance alleles with male breast cancer risk and clinicopathological characteristics: results from a multicenter study in Italy. Breast cancer research and treatment 138(3):861-868. doi:10.1007/s10549-013-2459-4.

6. Kuchenbaecker KB, Neuhausen SL, Robson M, Barrowdale D, McGuffog L, Mulligan AM, Andrulis IL, Spurdle AB, Schmidt MK, Schmutzler RK, Engel C, Wappenschmidt B, Nevanlinna H, Thomassen M, Southey M, Radice P, Ramus SJ, Domchek SM, Nathanson KL, Lee A, Healey S, Nussbaum RL, Rebbeck TR, Arun BK, James P, Karlan BY, Lester J, Cass I; Breast Cancer Family Registry, Terry MB, Daly MB, Goldgar DE, Buys SS, Janavicius R, Tihomirova L, Tung N, Dorfling CM, van Rensburg EJ, Steele L, v O Hansen T, Ejlertsen B, Gerdes AM, Nielsen FC, Dennis J, Cunningham J, Hart S, Slager S, Osorio A, Benitez J, Duran M, Weitzel JN, Tafur I, Hander M, Peterlongo P, Manoukian S, Peissel B, Roversi G, Scuvera G, Bonanni B, Mariani P, Volorio S, Dolcetti R, Varesco L, Papi L, Tibiletti MG, Giannini G, Fostira F, Konstantopoulou I, Garber J, Hamann U, Donaldson A, Brewer C, Foo C, Evans DG, Frost D, Eccles D; EMBRACE Study, Douglas F, Brady A, Cook J, Tischkowitz M, Adlard J, Barwell J, Ong KR, Walker L, Izatt L, Side LE, Kennedy MJ, Rogers MT, Porteous ME, Morrison PJ, Platte R, Eeles R, Davidson R, Hodgson S, Ellis S, Godwin AK, Rhiem K, Meindl A, Ditsch N, Arnold N, Plendl H, Niederacher D, Sutter C, Steinemann D, BogdanovaMarkov N, Kast K, Varon-Mateeva R, Wang-Gohrke S, Gehrig A, Markiefka B, Buecher B, Lefol C, Stoppa-Lyonnet D, Rouleau E, Prieur F, Damiola F; GEMO Study Collaborators, Barjhoux L, Faivre L, Longy M, Sevenet N, Sinilnikova OM, Mazoyer S, Bonadona V, Caux-Moncoutier V, Isaacs C, Van Maerken T, Claes K, Piedmonte M, Andrews L, Hays J, Rodriguez GC, Caldes T, de la Hoya M, Khan S, Hogervorst FB, Aalfs CM, de Lange JL, Meijers-Heijboer HE, van der Hout AH, Wijnen JT, van 
495

496

497

498

499

500

501

502

503

504

505

506

507

508

509

510

511

512

513

514

515

516

517

518

519

520

521

522

523

524

525

Roozendaal KE, Mensenkamp AR, van den Ouweland AM, van Deurzen CH, van der Luijt RB; HEBON, Olah E, Diez O, Lazaro C, Blanco I, Teulé A, Menendez M, Jakubowska A, Lubinski J, Cybulski C, Gronwald J, Jaworska-Bieniek K, Durda K, Arason A, Maugard C, Soucy P, Montagna M, Agata S, Teixeira MR; KConFab Investigators, Olswold C, Lindor N, Pankratz VS, Hallberg E, Wang X, Szabo CI, Vijai J, Jacobs L, Corines M, Lincoln A, Berger A, Fink-Retter A, Singer CF, Rappaport C, Kaulich DG, Pfeiler G, Tea MK, Phelan CM, Mai PL, Greene MH, Rennert G, Imyanitov EN, Glendon G, Toland AE, Bojesen A, Pedersen IS, Jensen UB, Caligo MA, Friedman E, Berger R, Laitman Y, Rantala J, Arver B, Loman N, Borg A, Ehrencrona H, Olopade OI, Simard J, Easton DF, Chenevix-Trench G, Offit K, Couch FJ, Antoniou AC; CIMBA. 2014. Associations of common breast cancer susceptibility alleles with risk of breast cancer subtypes in BRCA1 and BRCA2 mutation carriers. Breast cancer research 16(6):3416. doi:10.1186/s13058-014-0492-9.

7. Peterlongo P, Chang-Claude J, Moysich KB, Rudolph A, Schmutzler RK, Simard J, Soucy P, Eeles RA, Easton DF, Hamann U, Wilkening S, Chen B, Rookus MA, Schmidt MK, van der Baan FH, Spurdle AB, Walker LC, Lose F, Maia AT, Montagna M, Matricardi L, Lubinski J, Jakubowska A, Gómez Garcia EB, Olopade OI, Nussbaum RL, Nathanson KL, Domchek SM, Rebbeck TR, Arun BK, Karlan BY, Orsulic S, Lester J, Chung WK, Miron A, Southey MC, Goldgar DE, Buys SS, Janavicius R, Dorfling CM, van Rensburg EJ, Ding YC, Neuhausen SL, Hansen TV, Gerdes AM, Ejlertsen B, Jønson L, Osorio A, Martínez-Bouzas C, Benitez J, Conway EE, Blazer KR, Weitzel JN, Manoukian S, Peissel B, Zaffaroni D, Scuvera G, Barile M, Ficarazzi F, Mariette F, Fortuzzi S, Viel A, Giannini G, Papi L, Martayan A, Tibiletti MG, Radice P, Vratimos A, Fostira F, Garber JE, Donaldson A, Brewer C, Foo C, Evans DG, Frost D, Eccles D, Brady A, Cook J, Tischkowitz M, Adlard J, Barwell J, Walker L, Izatt L, Side LE, Kennedy MJ, Rogers MT, Porteous ME, Morrison PJ, Platte R, Davidson R, Hodgson SV, Ellis S, Cole T; EMBRACE, Godwin AK, Claes K, Van Maerken T, Meindl A, Gehrig A, Sutter C, Engel C, Niederacher D, Steinemann D, Plendl H, Kast K, Rhiem K, Ditsch N, Arnold N, Varon-Mateeva R, Wappenschmidt B, Wang-Gohrke S, Bressac-de Paillerets B, Buecher B, Delnatte C, Houdayer C, Stoppa-Lyonnet D, Damiola F, Coupier I, Barjhoux L, Venat-Bouvet L, Golmard L, Boutry-Kryza N, Sinilnikova OM, Caron O, 

ML, Rodriguez GC, Copeland LJ, de la Hoya M, Segura PP, Nevanlinna H, Aittomäki K, van Os TA, Meijers-Heijboer HE, van der Hout AH, Vreeswijk MP, Hoogerbrugge N, Ausems MG, van Doorn HC, Collée JM; HEBON, Olah E, Diez O, Blanco I, Lazaro C, Brunet J, Feliubadalo L, Cybulski C, Gronwald J, Durda K, Jaworska-Bieniek K, Sukiennicki G, Arason A, Chiquette J, Teixeira MR, Olswold C, Couch FJ, Lindor NM, Wang X, Szabo CI, Offit K, Corines M, Jacobs L, Robson ME, Zhang L, Joseph V, Berger A, Singer CF, Rappaport C, Kaulich DG, Pfeiler G, Tea MK, Phelan CM, Greene MH, Mai PL, Rennert G, Mulligan AM, Glendon G, Tchatchou S, Andrulis IL, Toland AE, Bojesen A, Pedersen IS, Thomassen M, Jensen UB, Laitman Y, Rantala J, von Wachenfeldt A, Ehrencrona H, Askmalm MS, Borg Å, Kuchenbaecker KB, McGuffog L, Barrowdale D, Healey S, Lee A, Pharoah PD, Chenevix-Trench G; KConFab Investigators, Antoniou AC, Friedman E. 2015. Candidate genetic modifiers for breast and ovarian cancer risk in BRCA1 and BRCA2 mutation carriers. Cancer Epidemiology Biomarkers and Prevention 24(1):308-16. doi:10.1158/1055-9965.

8. Feliubadaló L, Lopez-Doriga A, Castellsagué E, del Valle J, Menéndez M, Tornero E, Montes E, Cuesta R, Gómez C, Campos O, Pineda M, González S, Moreno V, Brunet J, Blanco I, Serra E, Capellá G, Lázaro C. 2013. Next-generation sequencing meets genetic diagnostics: development of a comprehensive workflow for the analysis of BRCA1 and BRCA2 genes. European journal of human genetics 21(8):864-870. doi:10.1038/ejhg.2012.270.

9. Yeo ZX, Wong JC, Rozen SG, Lee AS. 2014. Evaluation and optimisation of indel detection workflows for ion torrent sequencing of the BRCA1 and BRCA2 genes. BMC Genomics 15:516. doi:10.1186/1471-2164-15-516.

10. Trujillano D, Weiss ME, Schneider J, Köster J, Papachristos EB, Saviouk V, Zakharkina T, Nahavandi N, Kovacevic L, Rolfs A. 2015. Next-generation sequencing of the BRCA1 and BRCA2 genes for the genetic diagnostics of hereditary breast and/or ovarian cancer. The Journal of molecular diagnostics 17(2):162-170. doi:10.1016/j.jmoldx.2014.11.004.

11. O’Sullivan Coyne G, Chen A, Kummar S. 2015. Delivering on the promise: poly ADP ribose polymerase inhibition as targeted anticancer therapy. Current opinion in oncology 27(6):475-481. doi:10.1097/CCO.0000000000000238. 
557

558

559

560

561

562

563

564

565

566

567

568

569

570

571

572

573

574

575

576

577

578

579

580

581

582

583

584

585

586

587

12. Colicchia V, Petroni M, Guarguaglini G, Sardina F, Sahún-Roncero M, Carbonari M, Ricci B, Heil C, Capalbo C, Belardinilli F, Coppa A, Peruzzi G, Screpanti I, Lavia P, Gulino A, Giannini G. 2017. PARP inhibitors enhance replication stress and cause mitotic catastrophe in MYCN-dependent neuroblastoma. Oncogene 36(33):4682-4691. doi:10.1038/onc.2017.40.

13. Stewart RA, Pilié PG, Yap TA. 2018. Development of PARP and Immune-Checkpoint Inhibitor Combinations. Cancer research 78(24):6717-6725. doi:10.1158/0008-5472.

14. Coleman RL, Oza AM, Lorusso D, Aghajanian C, Oaknin A, Dean A, Colombo N, Weberpals JI, Clamp A, Scambia G, Leary A, Holloway RW, Gancedo MA, Fong PC, Goh JC, O'Malley DM, Armstrong DK, Garcia-Donas J, Swisher EM, Floquet A, Konecny GE, McNeish IA, Scott CL, Cameron T, Maloney L, Isaacson J, Goble S, Grace C, Harding TC, Raponi M, Sun J, Lin KK, Giordano H, Ledermann JA; ARIEL3 investigators. 2017. Rucaparib maintenance treatment for recurrent ovarian carcinoma after response to platinum therapy (ARIEL3): a randomised, double-blind, placebocontrolled, phase 3 trial. Lancet 390(10106):1949-1961. doi:10.1016/S01406736(17)32440-6.

15. Robson M, Im SA, Senkus E, Xu B, Domchek SM, Masuda N, Delaloge S, Li W, Tung N, Armstrong A, Wu W, Goessl C, Runswick S, Conte P. 2017. Olaparib for Metastatic Breast Cancer in Patients with a Germline BRCA Mutation. The New England journal of medicine 377(6):523-533. doi:10.1056/NEJMoa1706450.

16. Oza AM, Matulonis UA, Malander S, Hudgens S, Sehouli J, Del Campo JM, BertonRigaud D, Banerjee S, Scambia G, Berek JS, Lund B, Tinker AV, Hilpert F, Vázquez IP, D'Hondt V, Benigno B, Provencher D, Buscema J, Agarwal S, Mirza MR. 2018. Quality of life in patients with recurrent ovarian cancer treated with niraparib versus placebo (ENGOT-OV16/NOVA): results from a double-blind, phase 3, randomised controlled trial. Lancet Oncology 19(8):1117-1125. doi:10.1016/S1470-2045(18)30333-4.

17. Litton JK, Rugo HS, Ettl J, Hurvitz SA, Gonçalves A, Lee KH, Fehrenbacher L, Yerushalmi R, Mina LA, Martin M, Roché H, Im YH, Quek RGW, Markova D, Tudor IC, Hannah AL, Eiermann W, Blum JL. 2018. Talazoparib in Patients with Advanced Breast Cancer and a Germline BRCA Mutation. The New England journal of medicine 379(8):753-763. doi:10.1056/NEJMoa1802905. 
588

589

590

591

592

593

594

595

596

597

598

599

600

601

602

603

604

605

606

607

608

609

610

611

612

613

614

615

616

617

618

18. Voelkerding KV, Dames SA, Durtschi JD. 2009. Next-generation sequencing: from basic research to diagnostics. Clinical chemistry 55(4):641-658.

doi:10.1373/clinchem.2008.112789.

19. Rothberg JM, Hinz W, Rearick TM, Schultz J, Mileski W, Davey M, Leamon JH, Johnson K, Milgrew MJ, Edwards M, Hoon J, Simons JF, Marran D, Myers JW, Davidson JF, Branting A, Nobile JR, Puc BP, Light D, Clark TA, Huber M, Branciforte JT, Stoner IB, Cawley SE, Lyons M, Fu Y, Homer N, Sedova M, Miao X, Reed B, Sabina J, Feierstein E, Schorn M, Alanjary M, Dimalanta E, Dressman D, Kasinskas R, Sokolsky T, Fidanza JA, Namsaraev E, McKernan KJ, Williams A, Roth GT, Bustillo J. 2011. An integrated semiconductor device enabling non-optical genome sequencing. Nature 475(7356):348-352. doi:10.1038/nature10242.

20. Wallace AJ. 2016. New challenges for BRCA testing: a view from the diagnostic laboratory. European journal of human genetics 24 Suppl 1:S10-18. doi:10.1038/ejhg.2016.94.

21. Loman NJ, Misra RV, Dallman TJ, Constantinidou C, Gharbia SE, Wain J, Pallen MJ. 2012. Performance comparison of benchtop high-throughput sequencing platforms. Nature biotechnology 30(5):434-439. doi:10.1038/nbt.2198.

22. Capalbo C, Ricevuto E, Vestri A, Ristori E, Sidoni T, Buffone O, Adamo B, Cortesi E, Marchetti P, Scambia G, Tomao S, Rinaldi C, Zani M, Ferraro S, Frati L, Screpanti I, Gulino A, Giannini G. 2006. BRCA1 and BRCA2 genetic testing in Italian breast and/or ovarian cancer families: mutation spectrum and prevalence and analysis of mutation prediction models. Annals of oncology 17 Suppl 7:vii34-40. doi:10.1093/annonc/md1947.

23. Capalbo C, Ricevuto E, Vestri A, Sidoni T, Buffone A, Cortesi E, Marchetti P, Scambia G, Tomao S, Rinaldi C, Zani M, Ferraro S, Frati L, Screpanti I, Gulino A, Giannini G. 2006. Improving the accuracy of BRCA1/2 mutation prediction: validation of the novel country-customized IC software. European journal of human genetics 14(1):49-54.

24. Coppa A, Buffone A, Capalbo C, Nicolussi A, D'Inzeo S, Belardinilli F, Colicchia V, Petroni M, Granato T, Midulla C, Zani M, Ferraro S, Screpanti I, Gulino A, Giannini G. 2014. Novel and recurrent BRCA2 mutations in Italian breast/ovarian cancer families widen the ovarian cancer cluster region boundaries to exons 13 and 14. Breast cancer research and treatmen 148(3):629-635. doi:10.1007/s10549-014-3196-z. 
619 25. Belardinilli F, Capalbo C, Buffone A, Petroni M, Colicchia V, Ferraro S, Zani M,

620 Nicolussi A, D'Inzeo S, Coppa A, Screpanti I, Gulino A, Giannini G. 2015. Validation of

621 the Ion Torrent PGM sequencing for the prospective routine molecular diagnostic of

622 colorectal cancer. Clinical biochemistry 48(13-14):908-910.

623 doi:10.1016/j.clinbiochem.2015.04.003.

624 26. Giannini G, Capalbo C, Ottini L, Buffone A, De Marchis L, Margaria E, Vitolo D,

625 Ricevuto E, Rinaldi C, Zani M, Ferraro S, Marchetti P, Cortesi E, Frati L, Screpanti I,

626 Gulino A. 2008. Clinical classification of BRCA1 DNA missense variants: H1686Q is a novel pathogenic mutation occurring in the ontogenetically invariant THV motif of the N-terminal BRCT domain. Journal of clinical oncology 26(25):4212-4214; author reply 4214-4215. doi:10.1200/JCO.2008.18.2089.

631

632

633

634

27. Coppa A, Nicolussi A, D'Inzeo S, Capalbo C, Belardinilli F, Colicchia V, Petroni M, 2018. Optimizing the identification of risk-relevant mutations by multigene panel testing in selected hereditary breast/ovarian cancer families. Cancer medicine-7(1):46-55. doi: 10.1002/cam4.1251.

28. Schouten JP, McElgunn CJ, Waaijer R, Zwijnenburg D, Diepvens F, Pals G. 2002. Relative quantification of 40 nucleic acid sequences by multiplex ligation-dependent probe amplification. Nucleic acids research 30(12):e57.

29. Buffone A, Capalbo C, Ricevuto E, Sidoni T, Ottini L, Falchetti M, Cortesi E, Marchetti P, Scambia G, Tomao S, Rinaldi C, Zani M, Ferraro S, Frati L, Screpanti I, Gulino A, Giannini G. 2007. Prevalence of BRCA1 and BRCA2 genomic rearrangements in a cohort of consecutive Italian breast and/or ovarian cancer families. Breast cancer research and treatment 106(2):289-296.

30. Plon SE, Eccles DM, Easton D, Foulkes WD, Genuardi M, Greenblatt MS, Hogervorst FB, Hoogerbrugge N, Spurdle AB, Tavtigian SV; IARC Unclassified Genetic Variants Working Group. 2008. Sequence variant classification and reporting: recommendations for improving the interpretation of cancer susceptibility genetic test results. Human mutation 29(11):1282-1291. doi:10.1002/humu.20880.

31. De Leeneer K, Hellemans J, De Schrijver J, Baetens M, Poppe B, Van Criekinge W, De Paepe A, Coucke P, Claes K. 2011. Massive parallel amplicon sequencing of the breast 
cancer genes BRCA1 and BRCA2: opportunities, challenges, and limitations. Human

651

652

653

654

655

656

657

658

659

660

661

662

663

664

665

666

667

668

669

670

671

672

673

674

675

676

677

678

679

680 Mutation 32(3):335-344. doi:10.1002/humu.21428.

32. Michils G, Hollants S, Dehaspe L, Van Houdt J, Bidet Y, Uhrhammer N, Bignon YJ, Vermeesch JR, Cuppens H, Matthijs G. 2012. Molecular analysis of the breast cancer genes BRCA1 and BRCA2 using amplicon-based massive parallel pyrosequencing. Journal of Molecular Diagnostics 14(6): 623-630. doi:10.1016/j.jmoldx.2012.05.006

33. Chan M, Ji SM, Yeo ZX, Gan L, Yap E, Yap YS, Ng R, Tan PH, Ho GH, Ang P, Lee AS. 2012. Development of a next generation sequencing method for BRCA mutation screening: a comparison between a high-throughput and a benchtop platform, Journal of Molecular Diagnostics 14(6):602-612. doi:10.1016/j.jmoldx.2012.06.003.

34. Ellison G, Huang S, Carr H, Wallace A, Ahdesmaki M, Bhaskar S, Mills J. 2015. A reliable method for the detection of BRCA1 and BRCA2 mutations in fixed tumour tissue utilising multiplex PCR-based targeted next generation sequencing. BMC clinical pathology 15:5. doi:10.1186/s12907-015-0004-6.

35. Mafficini A, Simbolo M, Parisi A, Rusev B, Luchini C, Cataldo I, Piazzola E, Sperandio N, Turri G, Franchi M, Tortora G, Bovo C, Lawlor RT, Scarpa A. 2016. BRCA somatic and germline mutation detection in paraffin embedded ovarian cancers by nextgeneration sequencing. Oncotarget 7(2):1076-1083. doi:10.18632/oncotarget.6834.

36. Enyedi, Jaksa G, Pintér L, Sükösd F, Gyuris Z, Hajdu A, Határvölgyi E, Priskin K, Haracska L. 2016. Simultaneous detection of BRCA mutations and large genomic rearrangements in germline DNA and FFPE tumor samples. Oncotarget 7(38):6184561859. doi:10.18632/oncotarget.

37. Goldfeder RL, Priest JR, Zook JM, Grove ME, Waggott D, Wheeler MT, Salit M, Ashley EA. 2016. Medical implications of technical accuracy in genome sequencing. Genome medicine 8(1):24. doi:10.1186/s13073-016-0269-0.

38. Pilato B, Pinto R, De Summa S, Petriella D, Lacalamita R, Danza K, Paradiso A, Tommasi S. 2016. BRCA1-2 diagnostic workflow from next-generation sequencing technologies to variant identification and final report. Genes, chromosomes \& cancer 55(10):803-13. doi:10.1002/gcc.22383.

39. Yan B, Hu Y, Ng C, Ban KH, Tan TW, Huan PT, Lee PL, Chiu L, Seah E, Ng CH, Koay ES, Chng WJ. 2016. Coverage analysis in a targeted amplicon-based next-generation 
681

682

683

684

685

686

687

688

689

sequencing panel for myeloid neoplasms. Journal of Clinical Pathology 69(9):801-804. doi:10.1136/jclinpath-2015-203580.

40. Zanella I, Merola F, Biasiotto G, Archetti S, Spinelli E, Di Lorenzo, D. 2017. Evaluation of the Ion Torrent PGM sequencing workflow for the routine rapid detection of BRCA1 and BRCA2 germline mutations. Experimental and Molecular Pathology 102(2):314-320. doi:10.1016/j.yexmp.2017.03.001.

41. Hirotsu Y, Ooka Y, Sakamoto I, Nakagomi H, Omata, M. 2017. Simultaneous detection of genetic and copy number alterations in BRCA1/2 genes. Oncotarget 8(70):114463114473. doi:10.18632/oncotarget.22962. 


\section{Table $\mathbf{1}$ (on next page)}

$B R C A 1$ and $B R C A 2$ variants contained in the Training Set used for the optimization of the workflow

Abbreviations: del: deletion; dup: duplication; SNV: single nucleotide variant; Phred quality score: probability of incorrect call 


\begin{tabular}{|c|c|c|c|c|c|c|c|c|}
\hline variant & & gene & effect & type & $\begin{array}{c}\text { frequency } \\
(\%)\end{array}$ & $\begin{array}{c}\text { Phred } \\
\text { quality } \\
\text { score } \\
\end{array}$ & coverage & $\begin{array}{c}\text { coverage } \\
\text { var }\end{array}$ \\
\hline DNA level & protein level & & & & & & & \\
\hline c.5266dupC & p.Gln1756Profs & BRCA1 & pathogenic & dup & 50,7 & 4616 & 2362 & 1198 \\
\hline c.1504_1508delTTAAA & p.Leu502Alafs & BRCA1 & pathogenic & del & 481 & 1492,07 & 778 & 374 \\
\hline c.4964_4982del19 & p.Ser1655Tyrfs & BRCA1 & pathogenic & del & 39,6 & 50 & 844 & 334 \\
\hline c.5407-?_*(1_?)del & p.? & BRCA1 & pathogenic & exon $23-24$ del & 1 & 1 & 1 & 1 \\
\hline c.5075-?_5193+?del & p.? & BRCA1 & pathogenic & exon $18-19$ del & 1 & 1 & 1 & 1 \\
\hline NBR2delEX1_BRCA1delEX1-2 & p.? & $\begin{array}{l}\text { NBR2/ } \\
\text { BRCA1 }\end{array}$ & pathogenic & $\begin{array}{l}\text { exon } 1 \text { NBR2 del } \\
\text { exon 1-2 BRCA1 del }\end{array}$ & / & / & / & / \\
\hline c.7921_7926delGAATTTinsAG & p.Glu2641Argfs & BRCA2 & pathogenic & complex & 44,6 & 1094,44 & 673 & 300 \\
\hline c.246dupA & p.Glu83Argfs & BRCA2 & pathogenic & dup & 44,7 & 409,21 & 253 & 113 \\
\hline c.2806_2809delAAAC & p.Ala938Profs & BRCA2 & pathogenic & del & 48,2 & 1144,45 & 591 & 285 \\
\hline c. $516+1 \mathrm{G}>\mathrm{C}$ & p.? & BRCA2 & pathogenic & SNV & 49,3 & 4602,4 & 2286 & 1126 \\
\hline c. $7007 \mathrm{G}>\mathrm{A}$ & p.Arg2336His & BRCA2 & pathogenic & SNV & 48,4 & 1128,61 & 576 & 279 \\
\hline
\end{tabular}




\section{Table 2 (on next page)}

Mean quality control and coverage metrics in the Training Set and in the Validation Set samples 
1

\begin{tabular}{lcccc} 
& \multicolumn{2}{c}{ Chip314 $(\mathbf{n}=\mathbf{8 4})$} & \multicolumn{2}{c}{ Chip316 (n=63) } \\
\cline { 2 - 5 } & Mean & SD & Mean & SD \\
\hline Number of mapped reads & 122109 & 43431 & 244737 & 69845 \\
\hline Percent reads on target $(\%)$ & 96 & 0,03 & 97 & 0,02 \\
\hline Uniformity of base coverage $(\%)$ & 97 & 0,02 & 97 & 0,01 \\
\hline Average base coverage depth & 726 & 266 & 1504 & 379 \\
\hline
\end{tabular}

2

3 


\section{Table 3(on next page)}

$B R C A 1$ and $B R C A 2$ lower-performance and fwd/rev end to end unbalanced amplicons 
1

\begin{tabular}{|c|c|c|c|c|c|}
\hline Gene & Id amplicon & GC content & Self-annealing & GC clamp & $\begin{array}{c}\text { Hairpin } \\
\text { formation }\end{array}$ \\
\hline \multirow{3}{*}{$B R C A 1$} & & fwd $43 \%$ & l & l & / \\
\hline & AMPL225438570 & & & & \\
\hline & & rev $36 \%$ & I & / & / \\
\hline \multirow{3}{*}{$B R C A 2$} & & fwd $41 \%$ & l & l & / \\
\hline & AMPL223392219 & & & & \\
\hline & & rev $27 \%$ & YES & / & YES \\
\hline \multirow{3}{*}{$B R C A 2$} & & fwd $22 \%$ & YES & / & YES \\
\hline & AMPL223379892 & & & & \\
\hline & & rev $36 \%$ & YES & I & YES \\
\hline \multirow{3}{*}{$B R C A 2$} & & fwd $41 \%$ & l & / & l \\
\hline & AMPL223390724 & & & & \\
\hline & & rev $39 \%$ & l & / & / \\
\hline \multirow{3}{*}{$B R C A 2$} & & fwd $46 \%$ & YES & / & YES \\
\hline & AMPL225505032 & & & & \\
\hline & & rev $36 \%$ & YES & YES & l \\
\hline \multirow{3}{*}{$B R C A 2$} & & fwd 33\% & l & / & / \\
\hline & AMPL225504179 & & & & \\
\hline & & rev $36 \%$ & YES & YES & I \\
\hline \multirow{3}{*}{$B R C A 1$} & & fwd $38 \%$ & l & l & l \\
\hline & AMPL223735053 & & & & \\
\hline & & rev $48 \%$ & / & / & / \\
\hline \multirow{3}{*}{$B R C A 1$} & & fwd $46 \%$ & / & l & l \\
\hline & AMPL223413081 & & & & \\
\hline & & rev $28 \%$ & YES & / & YES \\
\hline \multirow{3}{*}{$B R C A 1$} & & fwd $48 \%$ & / & / & / \\
\hline & AMPL223712774 & & & & \\
\hline & & rev $39 \%$ & YES & 1 & YES \\
\hline \multirow{3}{*}{$B R C A 2$} & & fwd $24 \%$ & YES & / & YES \\
\hline & AMPL224626553 & & & & \\
\hline & & rev $50 \%$ & / & / & I \\
\hline
\end{tabular}




\begin{tabular}{|c|c|c|c|c|c|}
\hline \multirow{3}{*}{$B R C A 2$} & \multirow{3}{*}{ AMPL223938117 } & fwd $31 \%$ & l & YES & l \\
\hline & & & & & \\
\hline & & rev $39 \%$ & YES & / & YES \\
\hline \multirow{3}{*}{$B R C A 2$} & \multirow{3}{*}{ AMPL223512592 } & fwd $25 \%$ & YES & l & YES \\
\hline & & & & & \\
\hline & & $\operatorname{rev} 46 \%$ & l & / & l \\
\hline \multirow{3}{*}{$B R C A 2$} & \multirow{3}{*}{ AMPL225349438 } & fwd $38 \%$ & YES & l & YES \\
\hline & & & & & \\
\hline & & $\operatorname{rev} 42 \%$ & YES & / & l \\
\hline \multirow{3}{*}{$B R C A 2$} & \multirow{3}{*}{ AMPL223730984 } & fwd $50 \%$ & / & l & l \\
\hline & & & & & \\
\hline & & rev $41 \%$ & I & / & l \\
\hline \multirow{3}{*}{$B R C A 2$} & \multirow{3}{*}{ AMPL223515418 } & fw $39 \%$ & YES & / & YES \\
\hline & & & & & \\
\hline & & rev $55 \%$ & YES & / & 1 \\
\hline \multirow{3}{*}{ BRCA2 } & \multirow{3}{*}{ AMPL225441321 } & fw $52 \%$ & l & l & l \\
\hline & & & & & \\
\hline & & rev $48 \%$ & YES & / & YES \\
\hline \multirow{3}{*}{$B R C A 2$} & \multirow{3}{*}{ AMPL223959719 } & fw $38 \%$ & l & / & l \\
\hline & & & & & \\
\hline & & rev $41 \%$ & YES & l & YES \\
\hline
\end{tabular}

2

3 


\section{Table 4 (on next page)}

Performance of the NGS assay (NGS vs Sanger) evaluated in the training set (in brackets, values were obtained considering LGRs as FNs). 
1

\begin{tabular}{|l|c|c|c|}
\cline { 2 - 4 } \multicolumn{1}{c|}{} & $\boldsymbol{B} \boldsymbol{R} \boldsymbol{A} \boldsymbol{1}$ & $\boldsymbol{B R C A 2}$ & $\boldsymbol{B} \boldsymbol{R} \boldsymbol{A} \boldsymbol{A}+\boldsymbol{B} \boldsymbol{R} \boldsymbol{C A} \boldsymbol{2}$ \\
\hline Total variants & 68 & 111 & 179 \\
\hline Called positions per patient & 5989 & 10257 & 16246 \\
\hline Total called positions & 65879 & 112827 & 178706 \\
\hline TP & 61 & 110 & 171 \\
\hline FP & 7 & 1 & 8 \\
\hline TN & 65808 & 112716 & 178524 \\
\hline FN & $0(3)$ & 0 & $0(3)$ \\
\hline Sensitivity, TP/(TP + FN) & $100 \%(95,3 \%)$ & $100 \%$ & $100 \%(98,3 \%)$ \\
\hline Specificity, TN/(TN + FP) & $100 \%$ & $100 \%$ & $100 \%$ \\
\hline Positive predictive value (PPV), TP/(TP + FP) & $89,7 \%$ & $99,1 \%$ & $95,5 \%$ \\
\hline Negative predictive value (NPV), TN/(TN + FN) & $100 \%$ & $100 \%$ & $100 \%$ \\
\hline
\end{tabular}

2

3 


\section{Table 5 (on next page)}

$B R C A 1$ and $B R C A 2$ variants contained in the Validation Set

Abbreviations: del: deletion; dup: duplication; ins: insertion; SNV: single nucleotide variant 


\begin{tabular}{|c|c|c|c|c|c|}
\hline \multicolumn{2}{|c|}{ variant } & \multirow{2}{*}{ gene } & \multirow{2}{*}{ effect } & \multirow{2}{*}{ type } & \multirow{2}{*}{$\begin{array}{c}\text { Number of times a } \\
\text { variant was observed }\end{array}$} \\
\hline DNA & protein & & & & \\
\hline c.1360_1361delAG & p.Ser454Terfs & BRCA1 & pathogenic & del & 1 \\
\hline c.5062_5064delGTT & p.Val1688del & BRCA1 & pathogenic & del & 1 \\
\hline c.5266dupC & p.Gln1756Profs & BRCA1 & pathogenic & dup & 3 \\
\hline c. 1462 dupA & p.Thr488Asnfs & BRCA1 & pathogenic & dup & 1 \\
\hline c.1016dupA & p.Val340Glyfs & BRCA1 & pathogenic & dup & 1 \\
\hline c.3331_3334delCAAG & p.Glu1111Asnfs & BRCA1 & pathogenic & del & 1 \\
\hline c. $4117 \mathrm{G}>\mathrm{T}$ & p.Glu1373Ter & BRCA1 & pathogenic & $\mathrm{SNV}$ & 6 \\
\hline c. $1505 \mathrm{~T}>\mathrm{G}$ & p.Leu502Ter & BRCA1 & pathogenic & $\mathrm{SNV}$ & 1 \\
\hline c. $.5074+1 \mathrm{G}>\mathrm{T}$ & p.? & BRCA1 & pathogenic & SNV & 1 \\
\hline c. $181 \mathrm{~T}>\mathrm{G}$ & p.Cys61Gly & BRCA1 & pathogenic & $\mathrm{SNV}$ & 1 \\
\hline c.1016dupA & p.Val340Glyfs & BRCA1 & pathogenic & dup & 1 \\
\hline c.5335_5335delC & p.Gln1779Asnfs & BRCA1 & pathogenic & del & 1 \\
\hline c. $1881 \mathrm{C}>\mathrm{G}$ & (p.Val627=) & BRCA1 & Uncertain significance & SNV & 1 \\
\hline c. $5123 \mathrm{C}>\mathrm{A}$ & p.Ala1708Glu & BRCA1 & pathogenic & SNV & 1 \\
\hline c.9252_9255delAACAinsTT & p.Lys3084Asnfs & BRCA2 & pathogenic & complex & 1 \\
\hline c.4131_4132insTGAGGA & p.Thr1378_Gly1712delinsTer & BRCA2 & pathogenic & ins & 1 \\
\hline c. $1238 \_1238 \mathrm{delT}$ & p.Leu413Hisfs & BRCA2 & pathogenic & del & 1 \\
\hline c.5211_5214delTACT & p.Asp1737_1738delThrfs & BRCA2 & pathogenic & del & 1 \\
\hline c.5718_5719delCT & p.Leu1908Argfs & BRCA2 & pathogenic & del & 1 \\
\hline c 2684_2684delC & p.Ala895Valfs & BRCA2 & pathogenic & del & 1 \\
\hline c.6591_6592delTG & p.Glu2198Asnfs & BRCA2 & pathogenic & del & 1 \\
\hline c. $7007 \mathrm{G}>\mathrm{A}$ & p.Arg2336His & BRCA2 & pathogenic & SNV & 1 \\
\hline c. $7008-62 \mathrm{~A}>\mathrm{G}$ & p.? & BRCA2 & Uncertain significance & $\mathrm{SNV}$ & 1 \\
\hline c. 72 delA & p.Gly25Aspfs & BRCA2 & pathogenic & del & 1 \\
\hline c.6275_6276delTT & p.Leu2092Profs & BRCA2 & pathogenic & del & 1 \\
\hline
\end{tabular}


Figure 1

Coverage plots of BRCA1 and BRCA2 lower-performance amplicons from 147 samples (TS and VS samples)

$A$ and $B: B R C A 1$ and $B R C A 2$ amplicons that did not reach a minimum coverage of $100 \mathrm{x} ; \mathrm{C}, \mathrm{E}$ : percentage of $B R C A 1$ and $B R C A 2 \mathrm{fwd} / \mathrm{rev}$ unbalanced amplicons (minimum average depth in strand bias of 30x for each strand end to end); D and F: histogram of the mean read depth per fwd/rev end to end unbalanced amplicons in BRCA1 and BRCA2. Error bars represent +/the standard error (SE) of reads number.

A

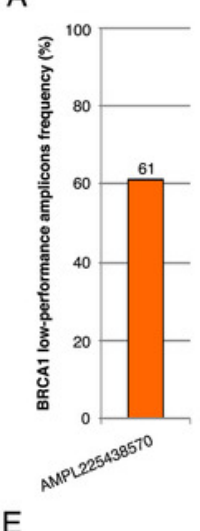

B

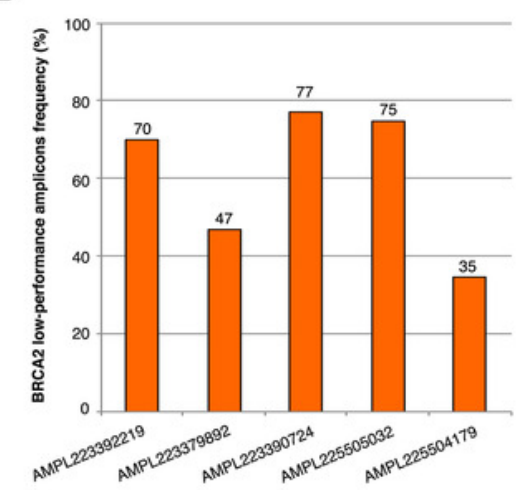

$E$

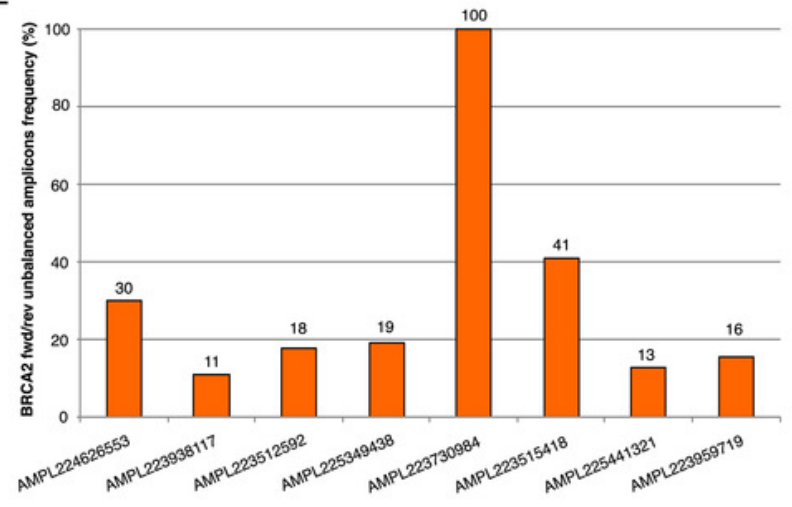

C

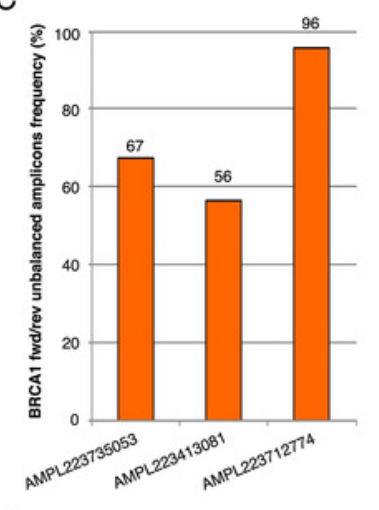

D

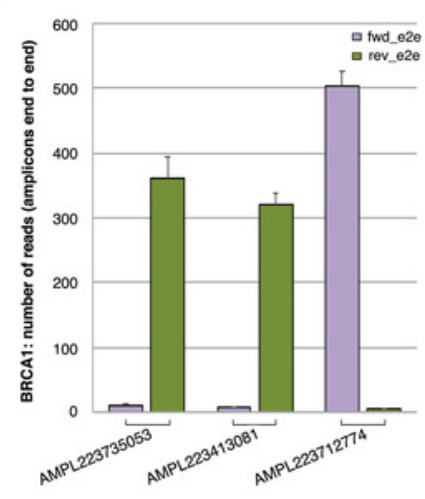

$\mathrm{F}$

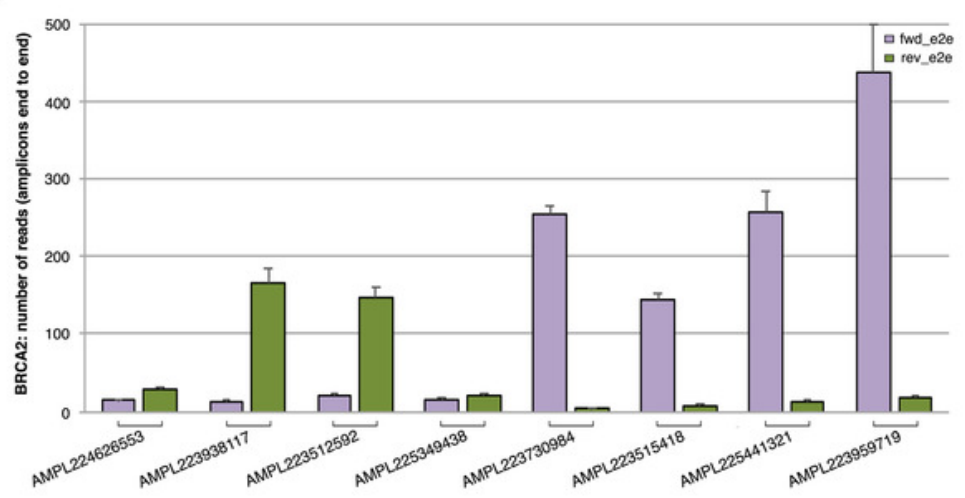


Figure 2

Representative image of read alignments visualized with IGV showing the germline mutations detected by NGS default analysis (A-F)
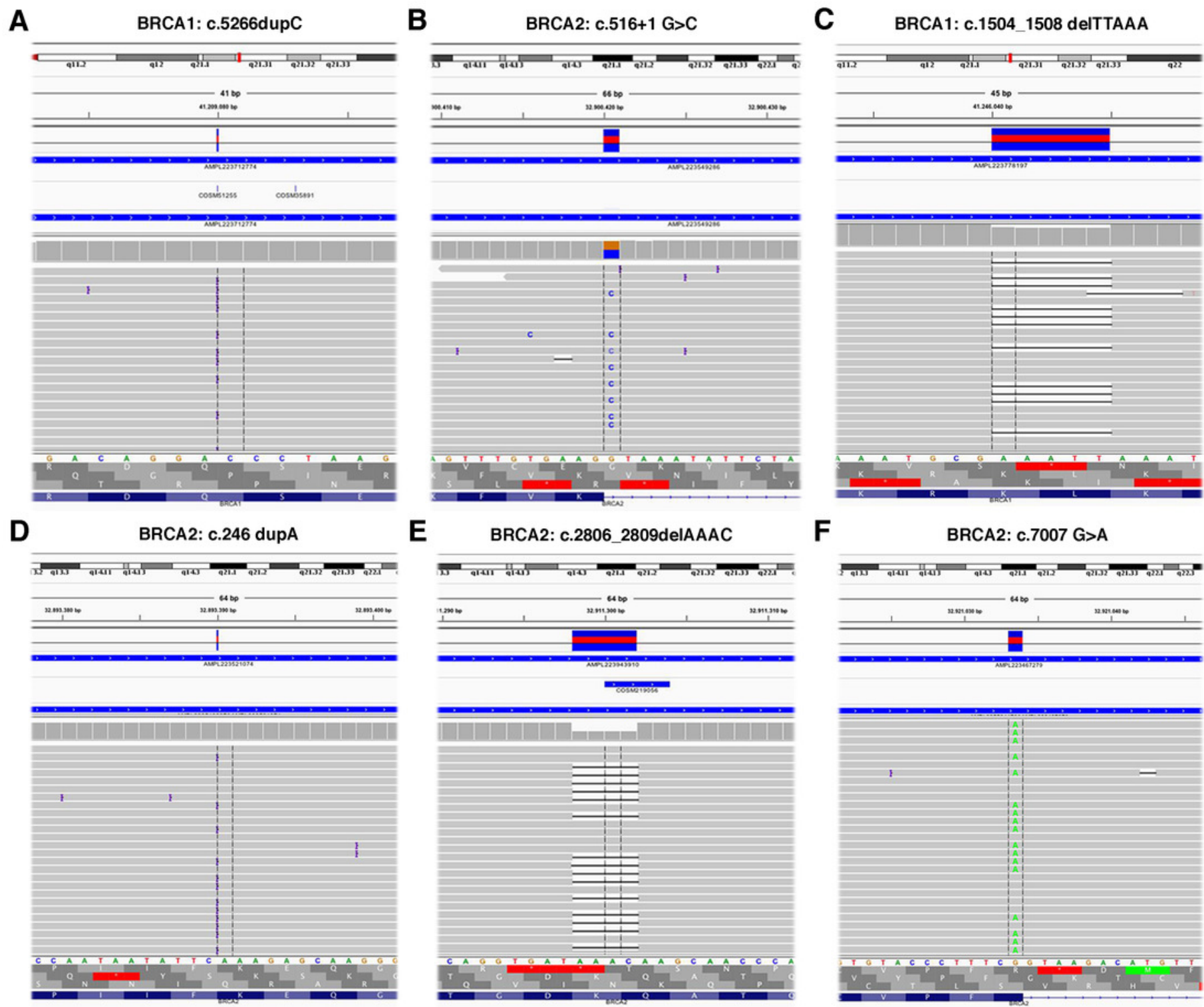

E

$\mathbf{F}$

BRCA2: $c .7007 \mathrm{G}>\mathrm{A}$
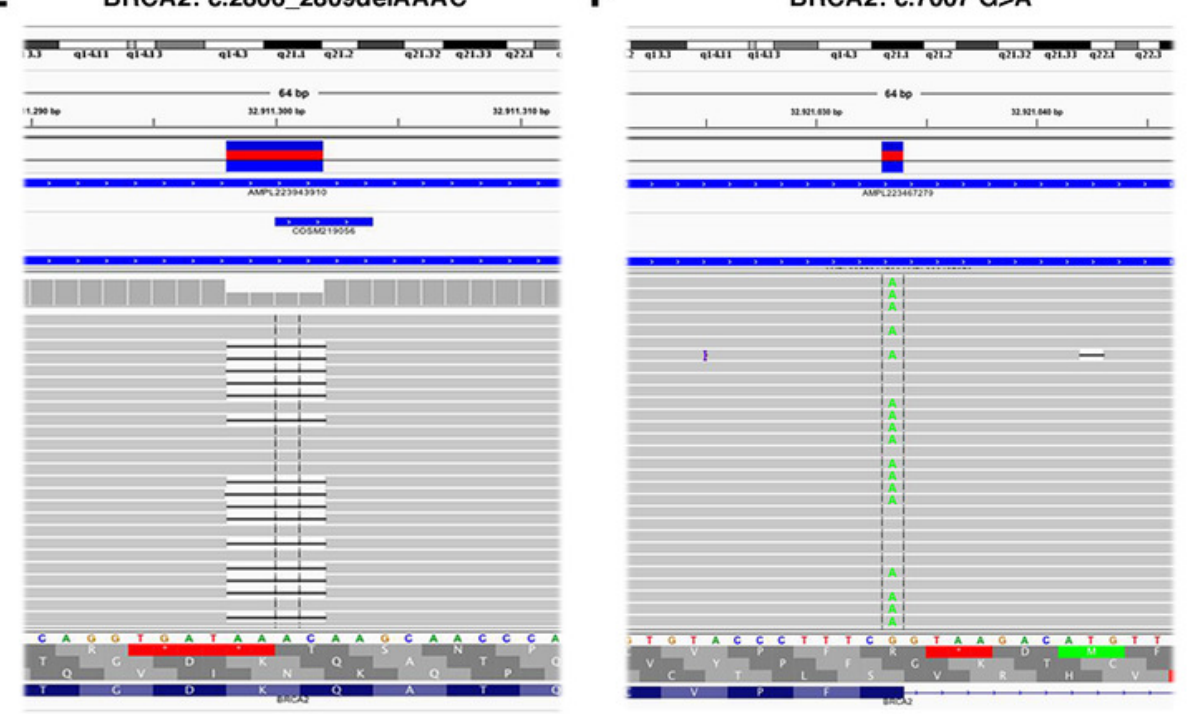


\section{Figure 3}

Representative image of read alignments showing the germline mutations of BRCAI and $B R C A 2$ detected by NGS analysis after minimal adjustments in the analytical pipeline of Torrent Suite Software.

Read alignments visualized with IGV showing the germline mutation of $B R C A 1$, c.4964_4982del19 (p.Ser1655Tyrfs) and BRCA2, c.7921_7926delGAATTTinsAG (p.Glu2641Argfs) (A and C). On the right side of the image, representative validation of NGS data by Sanger sequencing. Germline mutations were detected in the patients but not in the control subject. Arrows indicate the position of the mutated nucleotides ( $B$ and $D$ ). 
A

IGV

BRCA1: c.4964_4982del19
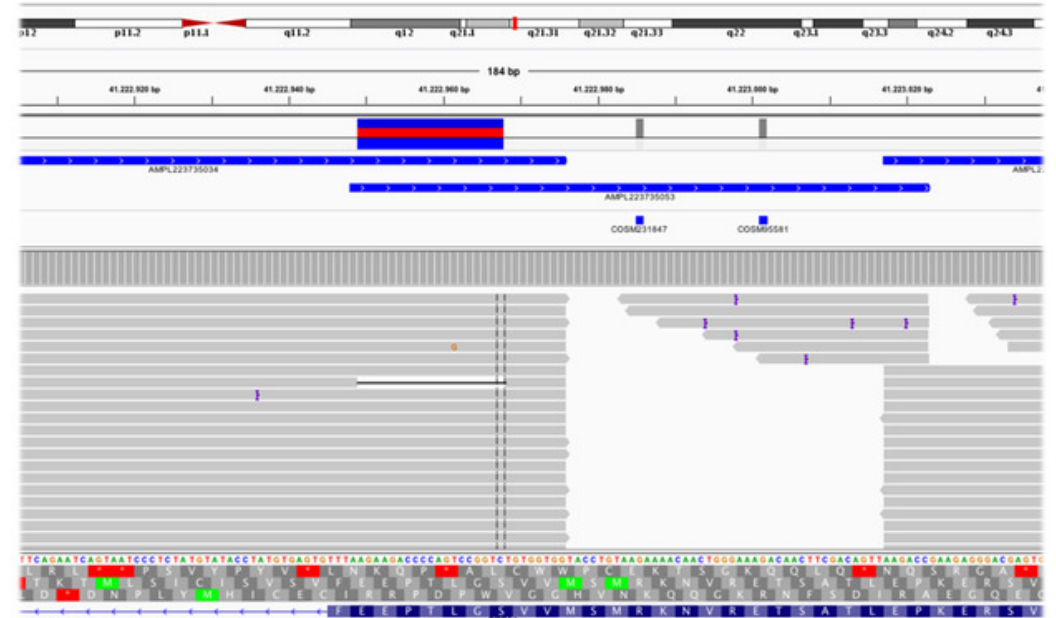

C

BRCA2: c.7921_7926delGAATTTinsAG

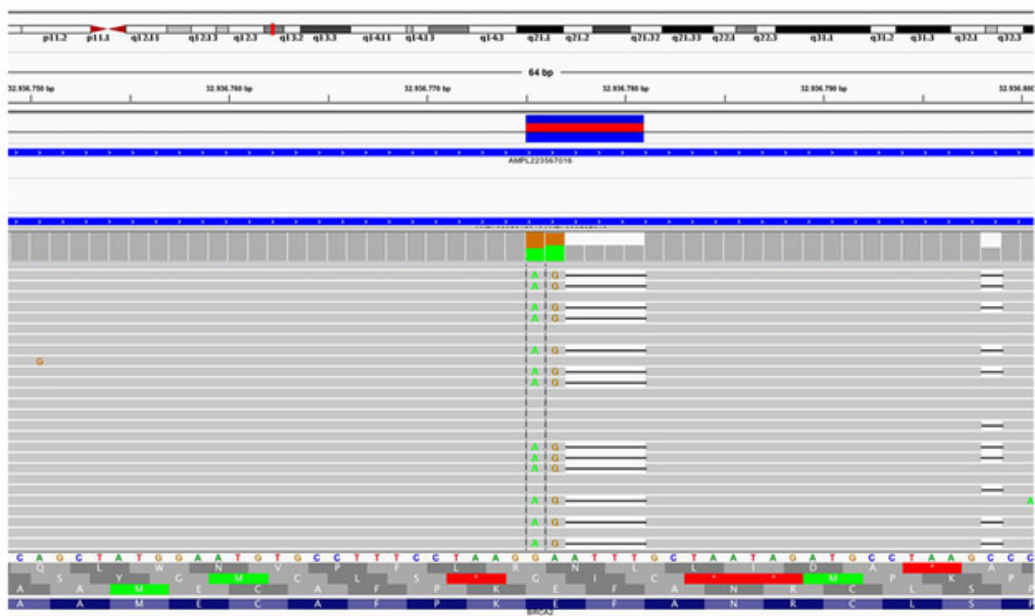

B Sanger sequencing

Control

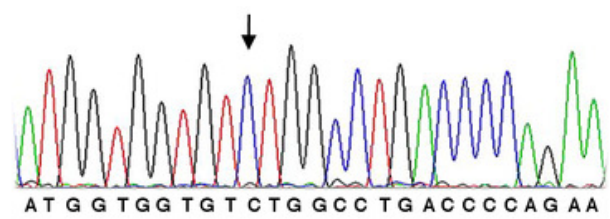

BRCA2: c.4964_4982del19

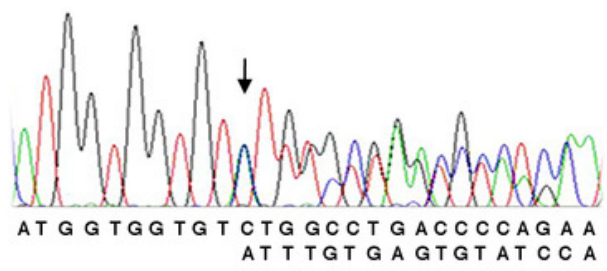

D

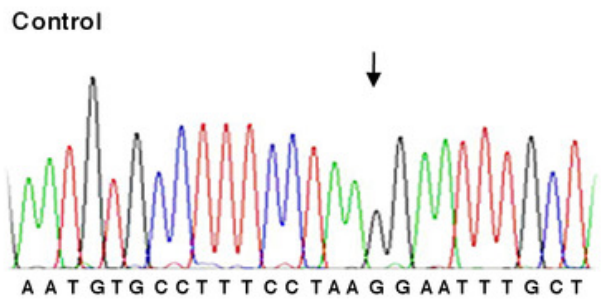

BRCA2: c.7921_7926delGAATT insAG

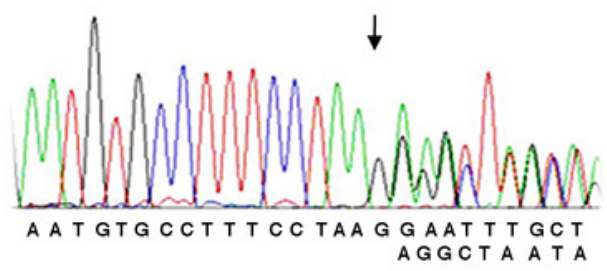


Figure 4

Workflow for analyzing BRCA1 and BRCA2 using NGS 

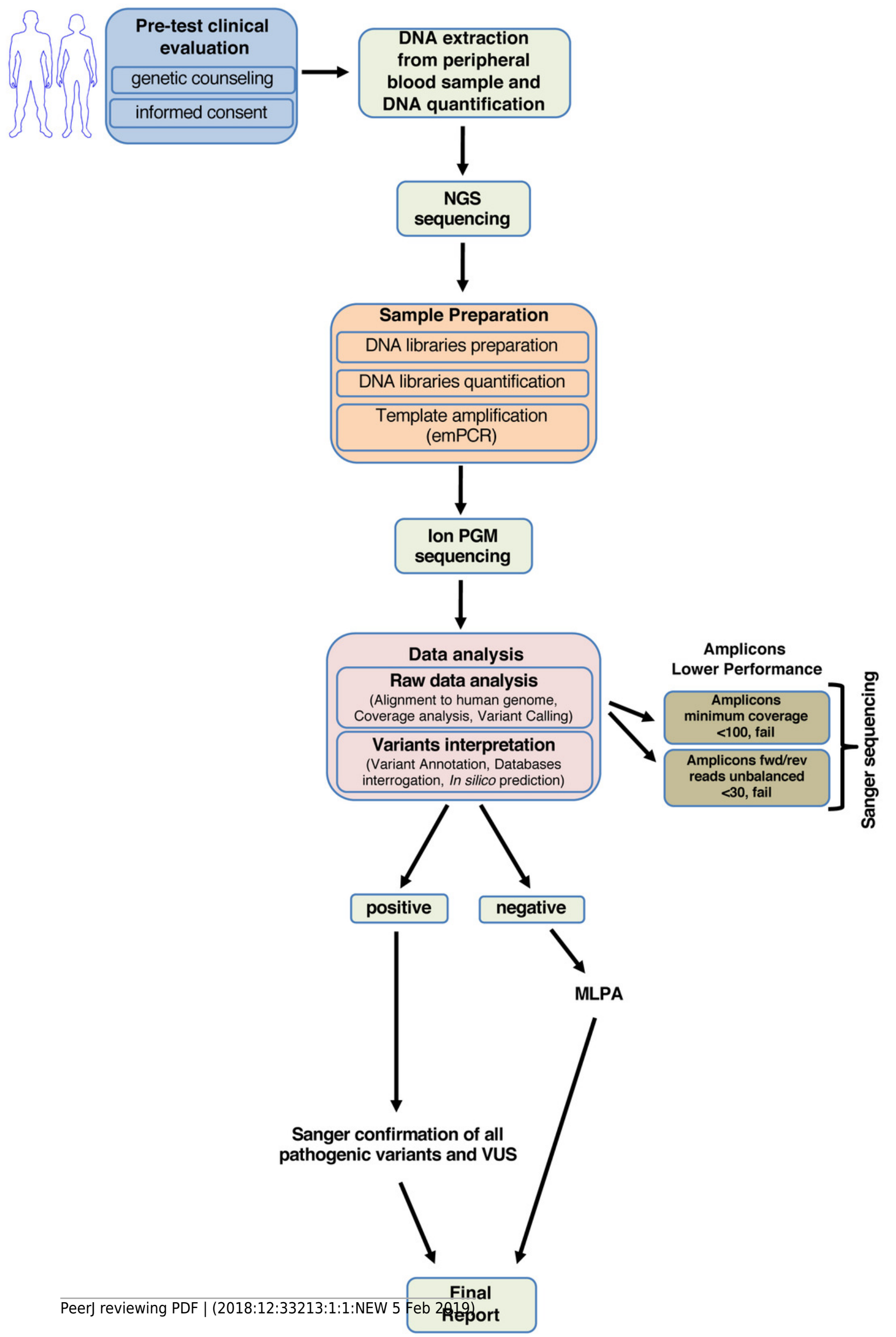